\title{
MODELING INSTABILITY IN THE CONTROL SYSTEM FOR HUMAN RESPIRATION: APPLICATIONS TO INFANT NON-REM SLEEP *
}

\author{
J. J. BATZEL ${ }^{\dagger}$ AND H. T. TRAN $\ddagger$
}

\begin{abstract}
Mathematical models of the human respiratory control system have been developed since 1940 to study a wide range of features of this complex system. The phenomena collectively referred to as periodic breathing (including Cheyne Stokes respiration and apneust ic breathing) have important medical implications. The hypothesis that periodic breathing is the result of delay in the feedback signals to the respiratory control system has been studied since the work of Grodins et al. in the early 1950's [36]. The purpose of this paper is to extend the model presented by Khoo et al. [60] in 1991 to include variable delay in the feedback control loop and to study the phenomena of periodic breathing and apnea as they occur during quiet sleep in infant sleep respiration at around 4 months of age. The nonlinear mathematical model consists of a feedback control system of five delay differential equations. Numerical simulations are performed to study instabilities in the control system and the occurence of periodic breathing and apnea in the above case which is a time frame of high incidence of sudden infant death syndrome (SIDS).
\end{abstract}

1. Introduction. In the absence of voluntary control of breathing or neurologically induced changes in breathing, the respiratory control system varies the ventilation rate in response to the levels of $\mathrm{CO}_{2}$ and $\mathrm{O}_{2}$ in the body. Models of the respiratory control system date back to 1905 when Haldane and Priestly discussed the negative feedback nature of ventilation control and $\mathrm{CO}_{2}$ regulation [43]. Quantitative studies began with Gray and his multiple factor theory of the control of ventilation in 1946 [33]. The first dynamic model of $\mathrm{CO}_{2}$ regulation using control theory was given by Grodins et al in a seminal paper in 1954 [37]. A number of important models have been proposed since then. Horgan and Lange 1963 [51] introduced transport delays into a model with a Gray type controller. This model could produce Cheyne-Stokes respiration. Later, Milhorn et al. (1965) [77] included cerebral blood flow and a Gray type controller responsive to $\mathrm{Pa}_{\mathrm{CO}_{2}}$ in the brain and $\mathrm{Pa}_{\mathrm{O}_{2}}$ in the arteries. The simulated response to a step increase in $\mathrm{CO}_{2}$ was higher than that observed experimentally. In 1967, Grodins et al. [35, 36] extended the earlier model to include variable delays, cerebral blood flow and a cerebral spinal fluid compartment modeling the effects of $\mathrm{pH}$ on ventilation. About the same time, Longobardo et al. (1966) [71] included a Lloyd and Cunningham type controller [67] among other features and could produce Cheyne-Stokes respiration under various conditions such as congestive heart condition. However, a large disturbance in ventilation was necessary to precipitate these responses. During the eighties, Longobardo et al. (1982) [72] introduced transitioning to the sleep state and a model for sleep apnea. Khoo et al. (1982) [60] developed a model in the same family as the Longobardo model which was used to study the stability properties of the respiratory control system. All of these models deal only with chemical control of respiration, not neural control. Comprehensive reviews of the history of respiratory models can be found in Khoo and Yamashiro [62] and Swanson et al. [112]. The model we are studying was proposed by Khoo, Kronauer, Strohl and Slutsky [60] and consists of a nonlinear system of delay differential equations with multiple delays. One application of this model is to study the

\footnotetext{
* Version January 26, 1999.

$\dagger$ Department of Mathematics, Box 8205, North Carolina State University, Raleigh, North Carolina, 27695-8205, (j jbatzel@unity .ncsu.edu)

\$Center for Research in Scientific Computation, Box 8205, North Carolina State University, Raleigh, North Carolina, 27695-8205, (tran@control.math.ncsu.edu).
} 
mechanisms producing unstable patterns of breathing such as periodic breathing and apnea, and specifically to investigate the hypothesis that such phenomena represent the manifestation of feedback-induced instabilities in the respiratory control system (see e.g. $[57,118,69,72,90,8,4]$ ). In 1991, Khoo extended the model to simulate respiration during sleep. Into this basic model we have incorporated in this paper: a) variable cardiac output using a model given in [28] thereby allowing the inclusion of variable delay in the feedback control loop. b) we extended the model to study infant sleep respiratory patterns including obstructive apnea and central apnea which may play a role in sudden infant death syndrome (SIDS).

The organization of the paper is as follows. We first review the physiology of the human respiratory system in sections 2 and 3 . Section 4 discusses periodic breathing and apnea. Section 5 describes the derivation of the mathematical model for the basic human respiration control system. In section 6 we extend the model to include variable cardiac output and variable delay. Numerical simulations of various physiological conditions are carried out in section 7 to study instability in respiratory control. Section 7.1 models the normal adult awake case. Section 7.2 simulates the congestive heart condition condition. Section 7.3 describes the adaptation of the model to include respiration during sleep including some aspects of the phenomenon of sleep apnea. Finally, section 7.4 describes the modeling of infant respiration. The normal awake condition is simulated in sec 7.4.1. The transition from the awake state to stage four sleep is simulated in section 7.4.2 and includes instabilities in respiration produced by apnea due to this transition. An analysis of the infant simulations is given in section 8 and several conclusions are drawn from this analysis.

2. The Human Respiratory System. The purpose of the respiratory system is to exchange the unwanted gas byproducts of metabolism, such as $\mathrm{CO}_{2}$, for $\mathrm{O}_{2}$, which is necessary for metabolism. The site of this exchange is the alveoli, small bubble-like sacs which are found in the lungs. There are approximately 300 million alveoli with a roughly spherical shape and a diameter of $.3 \mathrm{~mm}$. The alveoli represent a surface area of 50 to 100 square meters, by far the largest surface area of the body interfacing with the environment. Amazingly, this surface area encompasses a volume of only four liters. Intertwined among the alveoli are the smallest level of blood vessel, the capillaries. The blood-gas barrier between alveolus and capillary is extremely thin, allowing for efficient diffusion of gases in both directions. The lung generates this large diffusion area by branching the air pathway through approximately 23 generations of branches, terminating in the respiratory bronchioles which contain the alveolar ducts lined with alveoli where the gas transfer occurs. The pulmonary blood vessels also form a series of branching tubes starting from the pulmonary artery and terminating in the capillaries which are intertwined with the alveoli and then recombined into the pulmonary venous system. Gas transfer occurs between the capillaries and the alveoli. The capillaries form a dense network of tubes 10 microns in diameter in the walls of the alveoli resulting in an extremely thin blood-gas barrier. Mixed venous blood collected in the right ventricle of the heart is pumped into the pulmonary artery which branches successively, terminating in the capillaries. Each red blood cell spends approximately one second passing through two to three alveoli. The gas exchange boundary is so efficient that this is all the time needed for the red blood cells to completely exchange $\mathrm{CO}_{2}$ for $\mathrm{O}_{2}$ by passive diffusion. The blood is then collected back in the pulmonary veins and returned to the left auricle and then to the left ventricle where the blood is pumped to the systemic circulatory system (see Figure 1). Gas exchange is accomplished solely by passive diffusion ofgases across the 


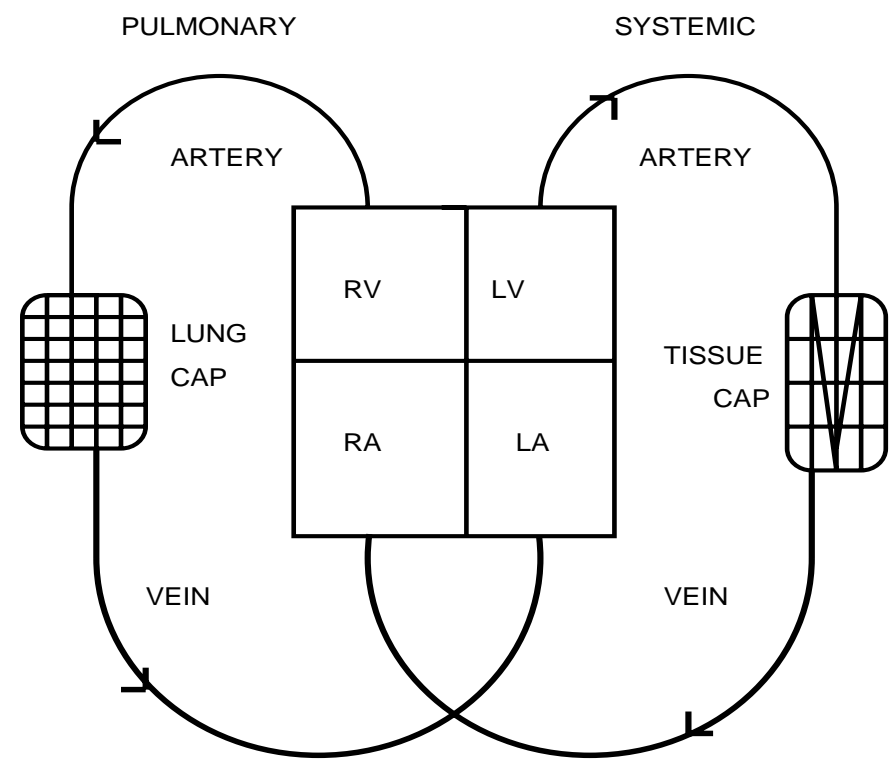

Fig. 1.

blood/gas barrier between capillaries and alveoli. The primary determiner of diffusion is the partial pressure gradients across this barrier. $\mathrm{O}_{2}$ diffuses into the capillaries and $\mathrm{CO}_{2}$ into the alveoli. $\mathrm{O}_{2}$ is carried in the red blood cell both in a simple dissolve state and bound to hemoglobin which increases the efficiency of absorption and storage. $\mathrm{CO}_{2}$ is carried in three different ways by the blood but, being twenty times more soluble than $\mathrm{O}_{2}$, the simple dissolved state is more significant for $\mathrm{CO}_{2}$. For efficient gas exchange, it is important that blood flow rate and ventilation (air flow) rate be matched within the various regions of the lung. For comprehensive references on respiratory physiology, see, for example [80, 126, 18, 82, 47, 104, 5].

3. Summary of the Control System for Respiration. The control mechanism which responds to the changing needs of the body to acquire oxygen and expel $\mathrm{CO}_{2}$ acts to maintain the levels of these gases within very narrow limits (and to a less understood degree match ventilation and blood flow). The means by which this is accomplished is fairly well understood and consists of three components:

- sensors which gather information;

- effectors which are nerve/muscle groups which control ventilation; and

- the control processor located in the brain which organizes information and sends commands to the effectors.

The sensory system consists of two main components: the central sensors and the peripheral sensors; see Figure 2. Since the control processor response to the central and peripheral sensor information is additive it is common practice to refer to the peripheral sensory system as the peripheral control and the central sensory system as the central control. The central sensors are found in the medulla area of the brain and respond to the level of $\mathrm{CO}_{2}$ partial pressure (and to $\mathrm{pH}$ levels as well, though the mechanism is not well understood [126]). $\mathrm{CO}_{2}$ partial pressure is the main factor stimulating ventilation [40]. The peripheral chemoreceptors are found in the carotid bodies located at the bifurcation of the common carotid arteries and the aortic bodies above and below the aortic arch [40]. These receptors respond to both $\mathrm{O}_{2}$ partial 


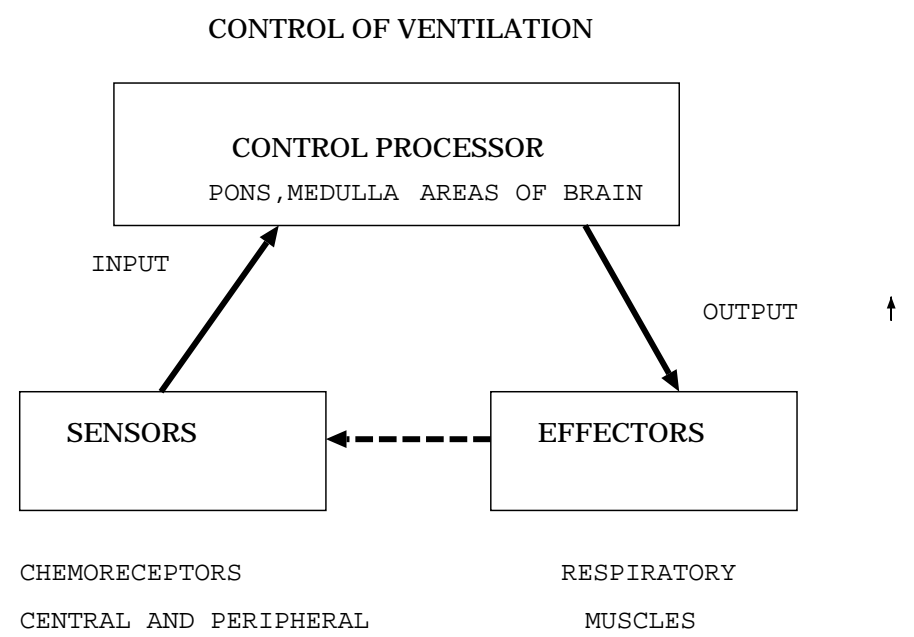

Fig. 2.

pressures and $\mathrm{CO}_{2}$ partial pressures. The carotid bodies also respond to $\mathrm{pH}$ levels and are much more important than the aortic bodies in respiratory control. Both the aortic and carotid bodies act to regulate the cardiovascular system as well [80]. The response of the peripheral receptors is swift due to the relatively high blood flow through the carotid bodies. The peripheral response to $\mathrm{CO}_{2}$ accounts for only $20 \%$ of the overall response due to $\mathrm{CO}_{2}$ partial pressure. The other $80 \%$ is due to the central receptors $[69,126]$. There are differences in the response profiles of peripheral and central receptors to $\mathrm{CO}_{2}$ and $\mathrm{O}_{2}$ levels resulting in a highly intricate set of possible response signals to the myriad of possible levels of $\mathrm{CO}_{2}$ and $\mathrm{O}_{2}$. The control system can thus respond successfully to a wide range of conditions. The sensitivity of this control is such that, regardless of the variation in the daily levels of rest and activity, the $\mathrm{CO}_{2}$ partial pressure remains within $3 \mathrm{~mm}$ of its normal level of $40 \mathrm{~mm} \mathrm{Hg}$ [126]. We refer the reader to $[126,65,13,4,25]$ for general references. Delay is introduced into the control system due to the physical distance which $\mathrm{CO}_{2}$ and $\mathrm{O}_{2}$ levels must be transported to the sensory sites before the ventilatory response can be adjusted. The delay in transfer of partial pressure information from lung to chemosensors depends on cardiac output in general and blood flow rate to the brain in particular. Thus it is important to know how cardiac output and blood flow rates to various tissue centers are controlled and in particular how they vary with $\mathrm{Pa}_{\mathrm{CO}_{2}}, \mathrm{P}_{\mathrm{O}_{2}}$ and $\mathrm{pH}$ (which are the quantities controlled by the respiratory system). A basic model proposed by Finchman and Tehrani [28] which describes cardiac output in terms of $\mathrm{Pa}_{\mathrm{CO}_{2}}$ and $\mathrm{Pa}_{\mathrm{O}_{2}}$ is incorporated into the model discussed here (again the $\mathrm{pH}$ issue is omitted). This cardiac output model allows for variable delay in the feedback control loop. There is an independent and local mechanism by which cerebral blood flow varies with $\mathrm{CO}_{2}$ and $\mathrm{O}_{2}$ levels in the brain. A model of this mechanism was developed by Khoo and is included in the model.

4. Periodic Breathing. Periodic breathing (PB) is the generic name given to a number of breathing patterns which are involuntary and have a regular pattern. The most important forms of PB [57] are:

- Cheyne-Stokes breathing which is illustrated in Figure 3; 
- apneustic breathing and

- Biots breathing.

A number of definitions have been given for PB. One definition by Parmalee [92] requires a minimum of two central involuntary respiratory events lasting less than ten seconds within twenty seconds of each other. Kelly and Shannon's definition is that two or three apneic pauses of three or more seconds occur with respiratory interruptions of not more than twenty seconds [109]. Periodic breathing patterns are abberations in normal breathing patterns and can have serious consequences. They appear in the following situations among others:

- patients with brain stem lesions;

- patients with congestive heart problems;

- normal individuals during sleep and at high altitudes; and

- newborn infants (which may be related to SIDS).

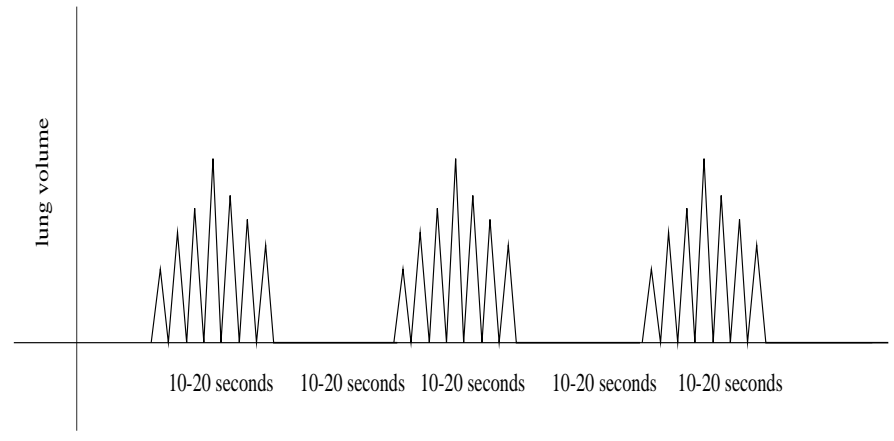

FiG. 3. Cheyne-Stokes respiration

A number of causes for PB have been proposed, including cardiovascular and neurological causes [57]. Perhaps the most widely held theory, introduced by Haldane and Douglas in 1909 [23], holds that PB is caused by instability in the respiratory control system. It appears that PB is mediated by the peripheral sensory mechanism and is effected by the delay in the feedback control loop. Significant delay in the feedback loop can result in the system reacting to information which no longer describes the state of the system. This can result in the so called "hunting phenomenon" where the system control response incorrectly adjusts the control response to stabilize a state which no longer obtains. Excessive or diminished controller gain also affects feedback effectiveness. Considered as a dynamical system with delay, well known mathematical results such as given in [16] show that long delay times in the feedback control loop will destabilize a system and produce oscillations.

Studies done to vary peripheral controller gain and feedback delay support this $[57,58]$. In particular, see [70], stability can be affected by:

- circulation delay times;

- central and peripheral control gain;

- hypoxia and control response to hypoxia; and

- sleep/arousal state.

The respiratory control system mechanism acts by means of negative feedback. Deviations in blood gas levels from physiological set points induce changes in ventilation rates which tend to compensate for these deviations. As mentioned above, the amount of blood flow to the peripheral sensors is extraordinary and thus medical problems restricting this flow may also be a cause for instability. 
The sensory mechanisms and the effector organs are separated by a physical distance and thereby introduce transport delays into the control system (see the above diagrams on the sensory and control systems). Corrective adjustments to ventilation will be thus delayed and together with changes in controller gain may lead to damped or sustained oscillations in the control system. Modeling studies have been done to test this hypothesis. See, for example, [71, 60]. Apnea (lack of ventilation) can occur when the oscillations in the ventilatory control signal drive the signal to the cutoff point. Apnea has been associated with the phenomenon of Sudden Infant Death Syndrome SIDS and thus a fuller understanding of mechanisms producing it is important [111].

\section{Model Equations.}

5.1. Nomenclature, parameter values and assumptions. The following symbol set is standard:

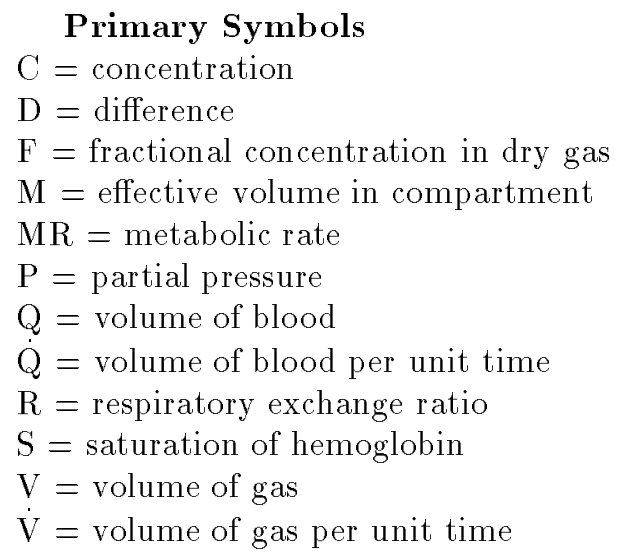

Secondary Symbols for Gas Phase

$\mathrm{A}=$ alveolar

$\mathrm{AT}=$ sea level air pressure

$\mathrm{B}=$ brain

$\mathrm{C}=$ carbon dioxide

$\mathrm{D}=$ dead space

$\mathrm{E}=$ expired

$\mathrm{I}=$ inspired

$\mathrm{L}=$ lung

$\mathrm{O}=$ oxygen

$\mathrm{T}=$ tissue

$\mathrm{W}=$ saturated air

\section{Secondary Symbols for Blood Phase}

$\mathrm{a}=$ mixed arterial

$\mathrm{c}=$ capillary

$\hat{c}=$ end-capillary

$\mathrm{i}=$ ideal

$\mathrm{m}=$ mixed

$\mathrm{v}=$ mixed venous

For example, $\mathrm{P}_{\mathrm{a}_{2}}$ indicates arterial partial pressure of $\mathrm{O}_{2}$ leaving the lungs and $\mathrm{C}_{\mathrm{T} \mathrm{CO}_{2}}$ represents the tissue compartment $\mathrm{CO}_{2}$ concentration. The following assumptions are incorporated into the model: 
- Partial pressure assumptions unless otherwise noted (time dependencies are suppressed for clarity):

$$
\begin{aligned}
& \mathrm{P}_{\mathrm{A}_{\mathrm{O}_{2}}}=\mathrm{P}_{\mathrm{O}_{\mathrm{O}_{2}}} \text {, } \\
& \mathrm{P}_{\mathrm{ACO}_{2}}=\mathrm{P}_{\mathrm{CO}_{2}} \text {, } \\
& \mathrm{P}_{\mathrm{B}_{\mathrm{CO}_{2}}}=\mathrm{P}_{\mathrm{B}_{\mathrm{CO}_{2}}} \text {, } \\
& \mathrm{P}_{\mathrm{B}_{\mathrm{O}_{2}}}=\mathrm{P}_{\mathrm{B}_{\mathrm{V}_{\mathrm{O}_{2}}}} \text {, } \\
& \mathrm{P}_{\mathrm{T}_{\mathrm{CO}_{2}}}=\mathrm{P}_{\mathrm{T}_{\mathrm{V}_{\mathrm{CO}_{2}}}} \text {, } \\
& \mathrm{P}_{\mathrm{T}_{\mathrm{O}_{2}}}=\mathrm{P}_{\mathrm{T}_{\mathrm{V}_{\mathrm{O}_{2}}}}
\end{aligned}
$$

where $\mathrm{v}=$ mixed venous blood.

- The alveoli and pulmonary capillaries are single well-mixed spaces.

- Constant temperature, pressure, and humidity are maintained in the gas compartment.

- Gas exchange is by diffusion.

- Acid/base buffering,material transfer across the blood brain barrier, and tissue buffering effects are ignored or greatly simplified [36].

- It is assumed that the left and right lungs behave alike, that airflows are the same in each lung and that the respiratory quotient (RQ is the ratio of inspired and expired air) is 0.8 . The effective lung volume is .75 of minute volume.

- No significant (2\%) intercardiac shunting occurs.

The parameter values in the tables (given in the Appendix) are traditional metric units:

$$
\begin{aligned}
& \text { pressure in } \mathrm{mm} \mathrm{Hg}, \\
& \text { temperature in centigrade, } \\
& \text { volume in liters, } \\
& \text { ambient pressure } 760 \mathrm{~mm} \mathrm{Hg} \text {. }
\end{aligned}
$$

Note that ventilation is conventionally reported at BTPS (body temperature, ambient pressure, saturated). In contrast, gas volumes in the blood are expressed as STPD (standard temperature and pressure dry). To convert a gas volume at STPD to BTPS the adjustment factor of $\frac{863}{\mathrm{P}_{\mathrm{AT}}-\mathrm{P}_{\mathrm{W}}}$ is used. The parameter values used in simulations are found in Tables 1 to 6 (see the Appendix) and sources for these values are indicated by references in the bibliography. The equations of the studied model arise from straight-forward development of mass balance equations which are rearranged through the application of basic physical laws.

5.2. Discussion of lung compartment model equations. We set up the basic mass transfer equation for alveolar volume and concentration of $\mathrm{CO}_{2}$ using Fick's law of diffusion:

$$
\frac{d \mathrm{~V}_{\mathrm{ACO}_{2}}}{d t}=\dot{\mathrm{Q}}\left[\mathrm{C}_{\mathrm{V}_{\mathrm{CO}_{2}}}-\mathrm{C}_{\mathrm{a}_{\mathrm{CO}_{2}}}\right]+\dot{\mathrm{V}}_{\mathrm{A}}\left[\mathrm{F}_{\mathrm{I}_{\mathrm{CO}_{2}}}-\mathrm{F}_{\mathrm{A}_{\mathrm{CO}_{2}}}\right],
$$

where

$$
\begin{aligned}
& \frac{d \mathrm{~V}_{\mathrm{A}_{\mathrm{CO}_{2}}}}{d t}=\text { change in lung } \mathrm{CO}_{2} \text { volume, } \\
& \dot{\mathrm{Q}}=\text { cardiac output }, \\
& \dot{\mathrm{V}}_{\mathrm{A}}=\text { alveolar ventilation (volume of gas entering } / \mathrm{min} \text { ), } \\
& \mathrm{F}_{\mathrm{A}}=\text { alveolar molar fractional part, }
\end{aligned}
$$




$$
\begin{aligned}
& \mathrm{F}_{\mathrm{I}}=\text { inspired gas molar fractional part, } \\
& \mathrm{C}_{\mathrm{a}}=\text { concentration of pulmonary blood leaving lungs, } \\
& \mathrm{C}_{\mathrm{v}}=\text { concentration of systemic venous blood entering the lungs. }
\end{aligned}
$$

Now using Dalton's Law:

we get:

$$
\begin{aligned}
& \mathrm{F}_{\mathrm{A}_{\mathrm{CO}_{2}}}=\frac{\mathrm{P}_{\mathrm{A}_{\mathrm{CO}_{2}}}}{\mathrm{P}_{\mathrm{AT}}-\mathrm{P}_{\mathrm{W}}}=\frac{\mathrm{V}_{\mathrm{A}_{\mathrm{CO}_{2}}}}{\mathrm{M}_{\mathrm{L}_{\mathrm{CO}_{2}}}} \\
& \mathrm{~F}_{\mathrm{I}_{\mathrm{CO}_{2}}}=\frac{\mathrm{P}_{\mathrm{I}_{\mathrm{CO}_{2}}}}{\mathrm{P}_{\mathrm{AT}}-\mathrm{P}_{\mathrm{W}}}=\frac{\mathrm{V}_{\mathrm{I}_{\mathrm{CO}_{2}}}}{\mathrm{LV}},
\end{aligned}
$$

$$
\mathrm{P}_{\mathrm{ACO}_{2}}=\frac{\mathrm{V}_{\mathrm{A}_{\mathrm{CO}_{2}}}}{\mathrm{M}_{\mathrm{L}_{\mathrm{CO}_{2}}}}\left(\mathrm{P}_{\mathrm{AT}}-\mathrm{P}_{\mathrm{W}}\right)
$$

Substituting into the above mass balance equation yields:

$$
\begin{aligned}
\frac{d \mathrm{P}_{\mathrm{AO}_{2}}}{d t} & =\frac{1}{\mathrm{M}_{\mathrm{L}_{\mathrm{CO}}}} \frac{d \mathrm{~V}_{\mathrm{A}_{\mathrm{CO}_{2}}}}{d t}\left(\mathrm{P}_{\mathrm{a}}-\mathrm{P}_{\mathrm{W}}\right) \\
& =\frac{1}{\mathrm{M}_{\mathrm{L}_{\mathrm{CO}_{2}}}}\left\{\dot{\mathrm{Q}}\left[\mathrm{C}_{\mathrm{V}_{\mathrm{CO}_{2}}}-\mathrm{C}_{\mathrm{a}_{\mathrm{CO}_{2}}}\right]\left(\mathrm{P}_{\mathrm{AT}}-\mathrm{P}_{\mathrm{W}}\right)+\dot{\mathrm{V}}_{\mathrm{A}}\left[\mathrm{P}_{\mathrm{I}_{\mathrm{CO}_{2}}}-\mathrm{P}_{\mathrm{ACO}_{2}}\right]\right\}
\end{aligned}
$$

Dissociation laws describe the concentration of a chemical carried in solution as a function of partial pressure and reflect such additional factors as hemoglobin binding or mitochondrial uptake. These laws represent a modification of Henry's Law. The same dissociation relationships are assumed to hold in mixed venous blood, body tissues and the brain. $\mathrm{K}_{\mathrm{CO}_{2}}$, the slope for $\mathrm{CO}_{2}$ dissociation, is assumed to be the same for all compartments. Now, for concentration measurements in dissociation laws, $\mathrm{C}_{\mathrm{VO}_{2}}$ and $\mathrm{C}_{\mathrm{C}_{2}}$ are experimentally measured in STPD. However, BTPS units are standard for ventilation values. Thus to match the parameter values to BTPS values, in the first term above we introduce the adjustment factor $\frac{863}{\mathrm{P}_{\mathrm{AT}}-\mathrm{P}_{\mathrm{W}}}$ which converts the concentration levels from STPD to BTPS (see, e.g., [126, 12]). We therefore get:

$$
\begin{aligned}
\frac{d \mathrm{P}_{\mathrm{A}_{\mathrm{CO}_{2}}}}{d t} & =\frac{1}{\mathrm{M}_{\mathrm{L}_{\mathrm{CO}}}}\left[\dot{\mathrm{Q}}\left[\mathrm{C}_{\mathrm{V}_{\mathrm{CO}_{2}}}-\mathrm{C}_{\mathrm{a}_{\mathrm{CO}_{2}}}\right] 863+\dot{\mathrm{V}}_{\mathrm{A}}\left[\mathrm{P}_{\mathrm{I}_{\mathrm{CO}_{2}}}-\mathrm{P}_{\mathrm{A}_{\mathrm{CO}_{2}}}\right]\right] \\
& =\frac{1}{\mathrm{M}_{\mathrm{L}_{\mathrm{CO}_{2}}}}\left[863 \dot{\mathrm{Q}} \mathrm{CO}_{2}\left[\mathrm{P}_{\mathrm{V}_{\mathrm{CO}_{2}}}-\mathrm{P}_{\mathrm{a}_{\mathrm{CO}_{2}}}\right]+\dot{\mathrm{V}}_{\mathrm{A}}\left[\mathrm{P}_{\mathrm{I}_{\mathrm{CO}_{2}}}-\mathrm{P}_{\mathrm{A}_{\mathrm{CO}_{2}}}\right]\right]
\end{aligned}
$$

where the units are BTPS and we use a linear dissociation law:

$$
\begin{aligned}
\mathrm{C}_{\mathrm{CO}_{2}} & =\mathrm{K}_{\mathrm{CO}_{2}} \mathrm{P}_{\mathrm{CO}_{2}}+\mathrm{K}_{1}, \\
\mathrm{C}_{\mathrm{VO}_{2}} & =\mathrm{K}_{\mathrm{CO}_{2}} \mathrm{P}_{\mathrm{V}_{\mathrm{CO}_{2}}}+\mathrm{K}_{1} .
\end{aligned}
$$

$\mathrm{K}_{\mathrm{CO}_{2}}$ and $\mathrm{K}_{1}$ are constants. We now assume that:

$$
\mathrm{P}_{\mathrm{ACO}_{2}}=\mathrm{P}_{\mathrm{aCO}_{2}}
$$


so that

$$
\frac{d \mathrm{P}_{\mathrm{A}_{\mathrm{CO}_{2}}}}{d t}=\frac{d \mathrm{P}_{\mathrm{a}_{\mathrm{CO}_{2}}}}{d t} .
$$

Also

$$
\dot{\mathrm{V}}_{\mathrm{A}}=\mathrm{EF}\left(\dot{\mathrm{V}}_{\mathrm{I}}-\dot{\mathrm{V}}_{\mathrm{D}}\right)
$$

The notation $\dot{V}_{I}$ stands for inspired minute volume and reflects the brain's effector response to the sensory information. This produces a breathing rate in liters per minute. $\dot{V}_{\mathrm{D}}$ represents dead space ventilation which is a fraction of airflow that does not reach the gas exchanging components of the lungs. $\dot{V}_{D}$ is also measured in liters per minute. EF is a proportionality constant reflecting the reduction in $\dot{V}_{A}$ at the alveolar-capillary boundary due to inefficiencies in gas exchange if they exist. There is also some drop in the partial pressure of $\mathrm{P}_{\mathrm{a}_{2}}$ (about $4-10 \mathrm{~mm} \mathrm{Hg}$ ) due to ventilation/perfusion mismatch and residual $\mathrm{R} / \mathrm{L}$ shunt [80]. This can be introduced by subtracting the mismatch value from $\mathrm{P}_{\mathrm{I}_{\mathrm{O}_{2}}}$.

Our first equation now becomes:

$$
\frac{d \mathrm{P}_{\mathrm{a}_{2}}}{d t}=\frac{1}{\mathrm{M}_{\mathrm{L}_{\mathrm{CO}_{2}}}}\left\{863 \dot{\mathrm{Q}} \mathrm{K}_{\mathrm{CO}_{2}}\left[\mathrm{P}_{\mathrm{V}_{\mathrm{CO}_{2}}}-\mathrm{P}_{\mathrm{a}_{\mathrm{CO}_{2}}}\right]+\mathrm{E}_{\mathrm{F}} \dot{\mathrm{V}}_{\mathrm{A}}\left[\mathrm{P}_{\mathrm{I}_{\mathrm{CO}_{2}}}-\mathrm{P}_{\mathrm{a}_{\mathrm{CO}_{2}}}\right]\right\} .
$$

A parallel argument results in the arterial equation

$$
\frac{d \mathrm{P}_{\mathrm{a}_{2}}}{d t}=\frac{863 \dot{\mathrm{Q}}\left[\mathrm{C}_{\mathrm{V}_{\mathrm{O}_{2}}}-\mathrm{C}_{\mathrm{a}_{\mathrm{O}_{2}}}\right]+\mathrm{E}_{\mathrm{F}} \dot{\mathrm{V}}_{\mathrm{A}}\left[\mathrm{P}_{\mathrm{I}_{\mathrm{O}_{2}}}-\mathrm{P}_{\mathrm{a}_{\mathrm{O}_{2}}}\right]}{\mathrm{M}_{\mathrm{L}_{\mathrm{O}_{2}}}}
$$

where we have left the equation written in terms of concentrations $\mathrm{C}_{\mathrm{V}_{\mathrm{O}_{2}}}$ and $\mathrm{Ca}_{\mathrm{O}_{2}}$. The dissociation laws for oxygen concentration are nonlinear and assumed differentiable. In numerical simulations the equations relating concentrations to partial pressures are assumed to be approximately piecewise linear and the relationships are given by

$$
\begin{gathered}
\mathrm{C}_{\mathrm{O}_{\mathrm{O}_{2}}}=\mathrm{m}_{\mathrm{v}} \mathrm{P}_{\mathrm{V}_{\mathrm{O}_{2}}}+\mathrm{B}_{\mathrm{v}}, \\
\mathrm{C}_{\mathrm{a}_{\mathrm{O}_{2}}}=\mathrm{m}_{\mathrm{a}} \mathrm{P}_{\mathrm{O}_{\mathrm{O}_{2}}}+\mathrm{B}_{\mathrm{a}} .
\end{gathered}
$$

where $m_{v}, m_{a}, B_{v}, B_{a}$ are constants which vary for large changes in partial pressure.

5.3. Discussion of brain compartment model equations. A compartment for the brain is necessary because the central chemoreceptors are in the brain and monitor the partial pressure of $\mathrm{CO}_{2}$ there. Therefore, only the mass balance equation for the brain compartment $\mathrm{CO}_{2}$ concentration needs to be derived. Again, using Fick's law, we obtain:

$$
\dot{\mathrm{V}}_{\mathrm{B}_{\mathrm{CO}_{2}}}=\dot{\mathrm{Q}}_{\mathrm{B}}\left(\mathrm{C}_{\mathrm{C}_{\mathrm{CO}_{2}}}-\mathrm{C}_{\mathrm{B}_{\mathrm{V}_{2}}}\right)+\mathrm{MR}_{\mathrm{B}_{\mathrm{CO}_{2}}},
$$

where $\dot{\mathrm{V}}_{\mathrm{B}_{\mathrm{CO}_{2}}}$ is the change in volume of $\mathrm{CO}_{2}$ in the brain and $\mathrm{MR}_{\mathrm{B}_{\mathrm{CO}}}$ is the metabolic production rate for $\mathrm{CO}_{2}$ in the brain. $\dot{\mathrm{Q}}_{\mathrm{B}}$ is blood flow to the brain. Dividing by the brain compartment volume $\mathrm{M}_{\mathrm{B}_{\mathrm{CO}}}$ yields:

$$
\frac{d \mathrm{C}_{\mathrm{B}_{2} \mathrm{O}_{2}}}{d t}=\frac{1}{\mathrm{M}_{\mathrm{B}_{\mathrm{CO}_{2}}}}\left[\mathrm{MR}_{\mathrm{B}_{\mathrm{CO}_{2}}}+\dot{\mathrm{Q}}_{\mathrm{B}}\left(\mathrm{C}_{\mathrm{a}_{\mathrm{CO}_{2}}}-\mathrm{C}_{\mathrm{B}_{\mathrm{CO}_{2}}}\right)\right] .
$$


We assume

$$
\mathrm{P}_{\mathrm{B}_{2}}=\mathrm{P}_{\mathrm{BV}_{\mathrm{CO}_{2}}} \Rightarrow \mathrm{C}_{\mathrm{B}_{\mathrm{CO}_{2}}}=\mathrm{C}_{\mathrm{B}_{\mathrm{CO}_{2}}} \text {. }
$$

We further assume that the dissociation laws are the same for the three compartments. Different constants hold for the venous and arterial systems of $\mathrm{O}_{2}$ but for $\mathrm{CO}_{2}$ the dissociation slope constants are the same for all three compartments and both venous and arterial systems.

Using the dissociation laws:

$$
\begin{aligned}
\mathrm{C}_{\mathrm{CO}_{2}} & =\mathrm{K}_{\mathrm{B}_{\mathrm{CO}_{2}}} \mathrm{P}_{\mathrm{CO}_{2}}+\mathrm{K}_{1}, \\
\mathrm{C}_{\mathrm{B}_{\mathrm{CO}_{2}}} & =\mathrm{K}_{\mathrm{B}_{\mathrm{CO}_{2}}} \mathrm{P}_{\mathrm{B}_{\mathrm{CO}_{2}}}+\mathrm{K}_{1}
\end{aligned}
$$

yields:

$$
\frac{d \mathrm{P}_{\mathrm{B}_{2}}}{d t}=\frac{\mathrm{MR}_{\mathrm{B}_{\mathrm{CO}_{2}}}}{\mathrm{M}_{\mathrm{B}_{2}} \mathrm{~K}_{\mathrm{B}_{\mathrm{CO}_{2}}}}+\frac{\left[\dot{\mathrm{Q}}_{\mathrm{B}}\left(\mathrm{P}_{\mathrm{a}_{\mathrm{CO}_{2}}}-\mathrm{P}_{\mathrm{B}_{\mathrm{CO}_{2}}}\right)\right]}{\mathrm{M}_{\mathrm{B}_{\mathrm{CO}_{2}}}} .
$$

5.4. General Tissue Compartment. This compartment models the returning mixed venous blood from all body tissues (the brain is considered part of the tissue compartment). Hence $\dot{\mathrm{Q}}=\dot{\mathrm{Q}}_{\mathrm{T}}$. The symbol v represents mixed venous blood (systemic system) leaving the tissue compartment. The mass balance equations for the tissue compartment $\mathrm{CO}_{2}$ and $\mathrm{O}_{2}$ concentrations are derived again by Fick's law:

$$
\begin{aligned}
\dot{\mathrm{V}}_{\mathrm{T}_{\mathrm{CO}_{2}}} & =\dot{\mathrm{Q}}_{\mathrm{T}}\left(\mathrm{C}_{\mathrm{a}_{\mathrm{CO}_{2}}}-\mathrm{C}_{\mathrm{V}_{\mathrm{CO}_{2}}}\right)+\mathrm{MR}_{\mathrm{T}_{\mathrm{CO}_{2}}}, \\
\dot{\mathrm{V}}_{\mathrm{T}_{\mathrm{O}_{2}}} & =\dot{\mathrm{Q}}_{\mathrm{T}}\left(\mathrm{C}_{\mathrm{a}_{\mathrm{CO}_{2}}}-\mathrm{C}_{\mathrm{V}_{\mathrm{O}_{2}}}\right)-\mathrm{MR}_{\mathrm{T}_{\mathrm{O}_{2}}},
\end{aligned}
$$

where $\dot{\mathrm{V}}_{\mathrm{T}_{\mathrm{CO}_{2}}}$ is the change in volume of $\mathrm{CO}_{2}$ in the tissue compartment, $\mathrm{MR}_{\mathrm{T}_{\mathrm{CO}_{2}}}$ is the metabolic production rate for $\mathrm{CO}_{2}$ in the tissue compartment, and $\mathrm{MR}_{\mathrm{T}_{\mathrm{O}_{2}}}$ is the metabolic utilization rate for $\mathrm{O}_{2}$ in the tissue compartment. We assume:

$$
\mathrm{P}_{\mathrm{T}_{\mathrm{CO}_{2}}}=\mathrm{P}_{\mathrm{V}_{\mathrm{CO}_{2}}} \Rightarrow \mathrm{C}_{\mathrm{T}_{\mathrm{CO}_{2}}}=\mathrm{C}_{\mathrm{V}_{\mathrm{CO}_{2}}} ; \dot{\mathrm{Q}}_{\mathrm{T}}=\dot{\mathrm{Q}} \text {. }
$$

By arguments completely parallel to those for the brain compartment we derive

$$
\frac{d \mathrm{P}_{\mathrm{V}_{\mathrm{O}_{2}}}}{d t}=\frac{\mathrm{MR}_{\mathrm{T}_{\mathrm{CO}_{2}}}}{\mathrm{M}_{\mathrm{T}_{\mathrm{CO}_{2}}} \mathrm{~K}_{\mathrm{CO}_{2}}}+\frac{\left[\dot{\mathrm{Q}}_{\mathrm{T}}\left(\mathrm{P}_{\mathrm{a}_{\mathrm{CO}_{2}}}-\mathrm{P}_{\mathrm{V}_{\mathrm{CO}_{2}}}\right)\right]}{\mathrm{M}_{\mathrm{T}_{\mathrm{CO}_{2}}}},
$$

where where $\mathrm{M}_{\mathrm{T}_{\mathrm{CO}}}$ is the effective venous blood volume of $\mathrm{CO}_{2}$ flowing from the tissue compartment. The equation for the $\mathrm{O}_{2}$ level in the tissue compartment is given as

$$
\frac{d \mathrm{C}_{\mathrm{V}_{\mathrm{O}_{2}}}}{d t}=\frac{-\mathrm{MR}_{\mathrm{T}_{\mathrm{O}_{2}}}}{\mathrm{M}_{\mathrm{T}_{\mathrm{O}_{2}}}}+\frac{\dot{\mathrm{Q}}_{\mathrm{T}}\left(\mathrm{C}_{\mathrm{O}_{\mathrm{O}_{2}}}-\mathrm{C}_{\mathrm{V}_{\mathrm{O}_{2}}}\right)}{\mathrm{M}_{\mathrm{T}_{\mathrm{O}_{2}}}},
$$

where $\mathrm{M}_{\mathrm{T}_{\mathrm{O}_{2}}}$ is the effective $\mathrm{O}_{2}$ volume. The equation for the $\mathrm{O}_{2}$ level in the tissue compartment is left in terms of concentrations $\mathrm{C}_{\mathrm{V}_{\mathrm{O}_{2}}}$ and $\mathrm{C}_{\mathrm{O}_{2}}$ since the dissociation law relating concentration to partial pressure is nonlinear (and differentiable). In simulations the dissociation law is approximated by a piecewise defined function given in $[59]$. 


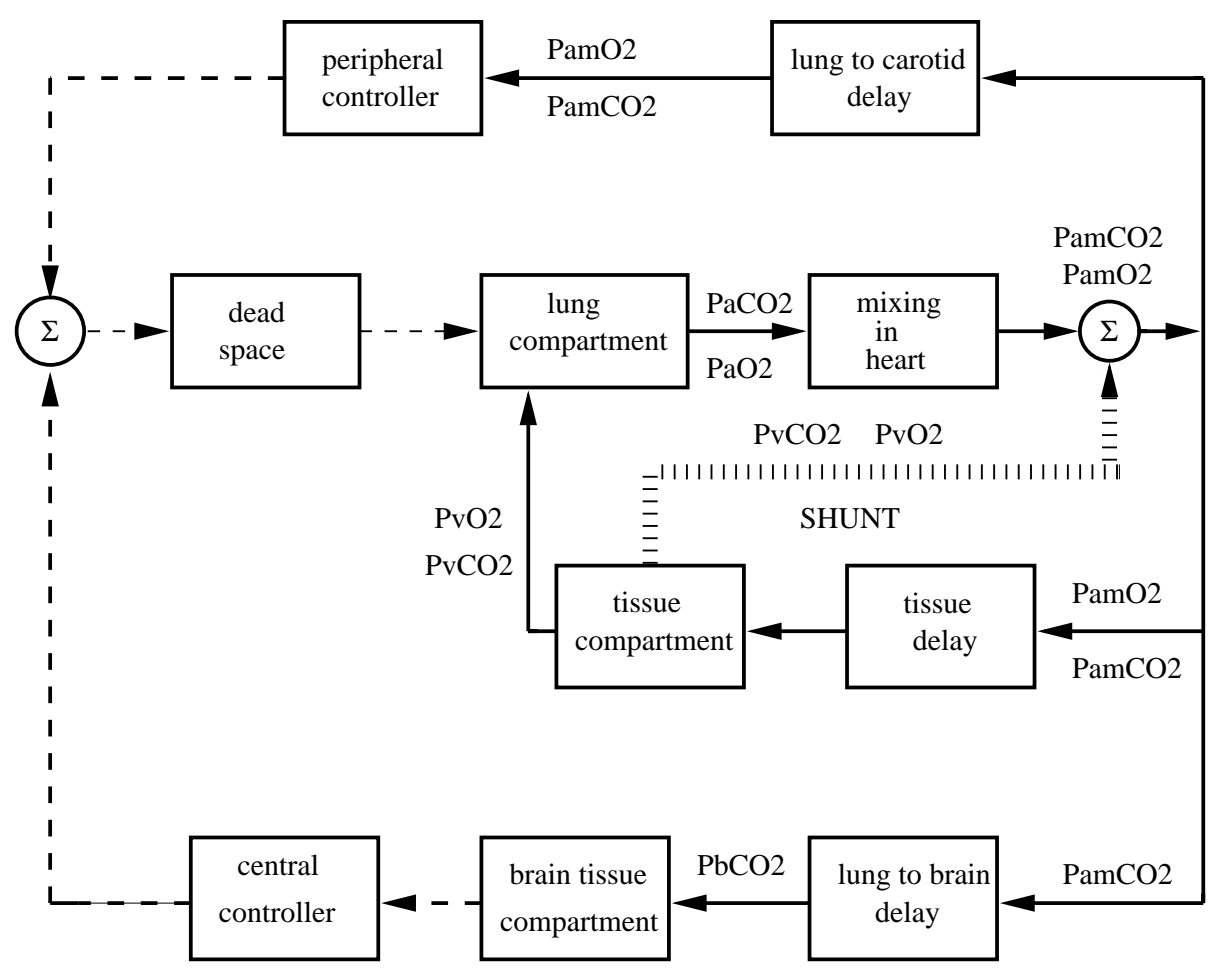

MODEL SCHEMATIC DIAGRAM WITH DELAYS

FIG. 4. Respiratory system delays

5.5. Introducing delay into the model. The following symbol set is used to indicate the variables:

$$
\begin{aligned}
& \tau_{\mathrm{B}}=\text { lung to brain delay } \\
& =\text { lung to tissue transport delay } \\
& \tau_{\mathrm{v}}=\text { venous side transport delay from tissue to lung } \\
& \tau_{\mathrm{a}}=\text { lung to carotid artery delay }
\end{aligned}
$$

Figure 4 shows a schematic diagram of how the delays are incorporated into the model. It is also noted that these delays vary with blood flow.

With the delays added to the model we have the following system of equations:

$$
\begin{aligned}
\frac{d \mathrm{P}_{\mathrm{CO}_{2}}(t)}{d t}= & \frac{863 \dot{\mathrm{Q}} \mathrm{K}_{\mathrm{CO}_{2}}\left[\mathrm{P}_{\mathrm{V}_{\mathrm{CO}_{2}}}\left(t-\tau_{\mathrm{V}}\right)-\mathrm{P}_{\mathrm{CO}_{2}}(t)\right]}{\mathrm{M}_{\mathrm{L}_{\mathrm{CO}_{2}}}}+\frac{\mathrm{E}_{\mathrm{F}} \dot{\mathrm{V}}_{\mathrm{A}}\left[\mathrm{P}_{\mathrm{I}_{\mathrm{CO}_{2}}}-\mathrm{P}_{\mathrm{a}_{\mathrm{O}_{2}}}(t)\right]}{\mathrm{M}_{\mathrm{L}_{\mathrm{O}_{2}}}} \\
\frac{d \mathrm{P}_{\mathrm{O}_{2}}(t)}{d t}=\frac{863 \dot{\mathrm{Q}}\left[\mathrm{C}_{\mathrm{O}_{2}}\left(t-\tau_{\mathrm{v}}\right)-\mathrm{C}_{\mathrm{O}_{2}}(t)\right]}{\mathrm{M}_{\mathrm{L}_{\mathrm{O}_{2}}}} & 11
\end{aligned}
$$




$$
\begin{aligned}
& +\frac{\mathrm{E}_{\mathrm{F}} \dot{\mathrm{V}}_{\mathrm{A}}\left[\mathrm{P}_{\mathrm{I}_{\mathrm{O}_{2}}}-\mathrm{P}_{\mathrm{a}_{\mathrm{O}_{2}}}(t)\right]}{\mathrm{M}_{\mathrm{L}_{\mathrm{O}_{2}}}}, \\
& \frac{d \mathrm{P}_{\mathrm{B}_{\mathrm{CO}_{2}}}(t)}{d t}=\frac{\mathrm{MR}_{\mathrm{B}_{\mathrm{CO}_{2}}}}{\mathrm{M}_{\mathrm{B}_{\mathrm{CO}_{2}}} \mathrm{~K}_{\mathrm{B}_{\mathrm{CO}}}}+\frac{\left[\dot{\mathrm{Q}}_{\mathrm{B}}\left(\mathrm{P}_{\mathrm{C}_{\mathrm{CO}_{2}}}\left(t-\tau_{\mathrm{B}}\right)-\mathrm{P}_{\mathrm{B}_{\mathrm{CO}_{2}}}(t)\right)\right]}{\mathrm{M}_{\mathrm{B}_{\mathrm{CO}_{2}}}}, \\
& \frac{d \mathrm{P}_{\mathrm{V}_{\mathrm{CO}_{2}}}(t)}{d t}=\frac{\mathrm{MR}_{\mathrm{T}_{\mathrm{CO}_{2}}}}{\mathrm{M}_{\mathrm{T}_{\mathrm{CO}_{2}}} \mathrm{~K}_{\mathrm{CO}_{2}}}+\frac{\left[\dot{\mathrm{Q}}_{\mathrm{T}}\left(\mathrm{P}_{\mathrm{a}_{\mathrm{CO}_{2}}}\left(t-\tau_{\mathrm{T}}\right)-\mathrm{P}_{\mathrm{V}_{\mathrm{CO}_{2}}}(t)\right)\right]}{\mathrm{M}_{\mathrm{T}_{\mathrm{CO}_{2}}}}, \\
& \frac{d \mathrm{C}_{\mathrm{V}_{\mathrm{O}_{2}}}(t)}{d t}=\frac{\dot{\mathrm{Q}}_{\mathrm{T}}\left[\mathrm{C}_{\mathrm{O}_{2}}\left(t-\tau_{\mathrm{T}}\right)-\mathrm{C}_{\mathrm{V}_{\mathrm{O}_{2}}}(t)\right]-\mathrm{MR}_{\mathrm{T}_{\mathrm{O}_{2}}}}{\mathrm{M}_{\mathrm{T}_{\mathrm{O}_{2}}}} \text {. }
\end{aligned}
$$

5.6. The Control Equation. The following control equation will be used in the model:

$$
\begin{aligned}
\dot{\mathrm{V}}_{\mathrm{I}}=\mathrm{G}_{\mathrm{P}} \exp \left(-.05 \mathrm{P}_{\mathrm{a}_{\mathrm{O}_{2}}}\left(t-\tau_{\mathrm{a}}\right)\right)\left(\mathrm{P}_{\mathrm{a}_{\mathrm{CO}_{2}}}\left(t-\tau_{\mathrm{a}}\right)-\mathrm{I}_{\mathrm{P}}\right) \\
+\mathrm{G}_{\mathrm{C}}\left(\mathrm{P}_{\mathrm{B}_{\mathrm{CO}_{2}}}(t)-\frac{\left.\mathrm{MR}_{\mathrm{B}_{\mathrm{CO}_{2}}}-\mathrm{I}_{\mathrm{C}}\right) .}{\mathrm{K}_{\mathrm{CO}_{2}} \dot{\mathrm{Q}}_{\mathrm{B}}}\right.
\end{aligned}
$$

This equation is derived based on the following observations. There are two fundamental mechanisms controlling the ventilation rate $\dot{\mathrm{V}}_{\mathrm{I}}$ : the central controller and the peripheral controller. In fact, the above model for the control variable is derived based on the following observations:

- The central controller responds exclusively to $\mathrm{P}_{\mathrm{CO}_{2}}$ via production of $\mathrm{H}^{+}$ions. (hypoxia-independent) [126].

- The peripheral controller consists of the carotid receptors found in the angle of the bifurcation of the common carotid arteries, as well as chemoreceptors in the aortic arch. They respond to both $\mathrm{O}_{2}$ and $\mathrm{CO}_{2}$ via $\mathrm{P}_{\mathrm{CO}_{2}}$ and $\mathrm{P}_{\mathrm{O}_{2}}$ (hypoxia dependent) [126].

- For fixed $\mathrm{P}_{\mathrm{O}_{2}}, \dot{\mathrm{V}}_{\mathrm{I}}$ varies linearly with $\mathrm{P}_{\mathrm{CO}_{2}}$.

- The effect of $\mathrm{P}_{\mathrm{O}_{2}}$ on $\dot{\mathrm{V}}_{\mathrm{I}}$ for fixed $\mathrm{P}_{\mathrm{CO}_{2}}$ is exponential [126].

- Berger and West $[4,126]$ indicate that the peripheral $\mathrm{P}_{\mathrm{O}_{2}}$ interacts multiplicatively with the peripheral $\mathrm{P}_{\mathrm{CO}_{2}}$ effect.

- The effect of the peripheral controller represents approximately $25 \%$ of the overall control stimulus response to $\mathrm{P}_{\mathrm{CO}_{2}}$ [126].

- The peripheral and central control effects are additive [19].

Thus:

$$
\dot{\mathrm{V}}_{\mathrm{I}}=\dot{\mathrm{V}}_{\text {periph }}+\dot{\mathrm{V}}_{\text {cent }},
$$

where $\dot{V}_{\text {cent }}$ is the ventilation due to the central control signal and $\dot{V}_{\text {periph }}$ is the ventilation due to the peripheral control signal. Physiologically, we do not assign any meaning to a negative $\dot{V}_{I}, \dot{V}_{\text {periph }}$ or $\dot{V}_{\text {cent }}$. Let $\dot{V}_{P}$ be the function defining ventilation due to the peripheral control signal and $\dot{V}_{C}$ be the function defining ventilation due to the central control signal. Then, we set $\dot{V}_{P}$ and $\dot{V}_{C}$ equal to zero should these functions become negative. Using the following notation

$$
[[x]]=\left\{\begin{array}{ll}
x & \text { for } x \geq 0 \\
0 & \text { for } x<0
\end{array} .\right.
$$

the control equation actually takes the form

$$
\dot{\mathrm{V}}_{\mathrm{I}}=\left[\left[\dot{\mathrm{V}}_{\mathrm{P}}\right]\right]+\left[\left[\dot{\mathrm{V}}_{\mathrm{C}}\right]\right]
$$


However, to simplify our discussion, we will omit this notation while always maintaining that the peripheral and central ventilation rates will be greater than or equal to zero. For the peripheral control we will use:

$$
\left.\dot{\mathrm{V}}_{\mathrm{P}}=\mathrm{G}_{\mathrm{P}} \exp \left(-.05 \mathrm{P}_{\mathrm{O}_{2}}(t)\right)\left(\mathrm{P}_{\mathrm{a}_{\mathrm{CO}_{2}}}(t)-\mathrm{I}_{\mathrm{P}}\right)\right),
$$

with $G_{P}$ denotes the peripheral gain factor, $I_{P}$ denotes the apneic threshold for peripheral $\mathrm{CO}_{2}$ response, and $\mathrm{Pa}_{\mathrm{CO}_{2}}$ denotes the arterial partial pressure $\mathrm{CO}_{2}$ at the entrance. An equation for $\dot{V}_{C}$ is established in $[98,78]$ for the steady state response of $\dot{\mathrm{V}}_{\mathrm{C}}$ to a step increase of $\mathrm{P}_{\overline{\mathrm{a}}_{\mathrm{CO}_{2}}}$ and is given by:

$$
\left.\dot{\mathrm{V}}_{\mathrm{C}}=\mathrm{G}_{\mathrm{C}}\left(\mathrm{P}_{\overline{\mathrm{a}}_{\mathrm{CO}_{2}}}-\mathrm{I}_{\mathrm{C}}\right)\right)
$$

where $I_{C}$ is the apneic threshold, $G_{C}$ is the controller gain, and $P_{\bar{a}_{C O_{2}}}$ is the arterial partial pressure $\mathrm{CO}_{2}$ at the entrance to the brain compartment.

However the central controller has been shown to react to $\mathrm{P}_{\mathrm{BCO}_{2}}$. The relation between $\mathrm{P}_{\mathrm{B}_{\mathrm{CO}_{2}}}$ and $\mathrm{P}_{\mathrm{a}_{\mathrm{CO}_{2}}}$ comes from solving at steady state the following differential equation:

$$
\frac{d \mathrm{P}_{\mathrm{B}_{\mathrm{CO}_{2}}}(t)}{d t}=\frac{\mathrm{MR}_{\mathrm{B}_{\mathrm{CO}_{2}}}}{\mathrm{M}_{\mathrm{B}_{\mathrm{CO}_{2}}} \mathrm{~K}_{\mathrm{B}_{\mathrm{CO}_{2}}}}+\frac{\left[\dot{\mathrm{Q}}_{\mathrm{B}}\left(\mathrm{P}_{\overline{\mathrm{a}}_{\mathrm{CO}_{2}}}(t)-\mathrm{P}_{\mathrm{B}_{\mathrm{CO}_{2}}}(t)\right)\right]}{\mathrm{M}_{\mathrm{B}_{\mathrm{CO}}}} .
$$

Suppressing time dependencies for clarity we have:

$$
\frac{d \mathrm{P}_{\mathrm{B}_{\mathrm{CO}_{2}}}}{d t}=\frac{\mathrm{MR}_{\mathrm{B}_{\mathrm{CO}_{2}}}}{\mathrm{M}_{\mathrm{B}_{\mathrm{CO}_{2}}} \mathrm{~K}_{\mathrm{CO}_{2}}}+\frac{\left[\dot{\mathrm{Q}}_{\mathrm{B}}\left(\mathrm{P}_{\overline{\mathrm{A}}_{\mathrm{CO}_{2}}}-\mathrm{P}_{\mathrm{B}_{\mathrm{CO}_{2}}}\right)\right]}{\mathrm{M}_{\mathrm{B}_{\mathrm{CO}_{2}}}},
$$

which implies

$$
\mathrm{P}_{\overline{\mathrm{a}}_{\mathrm{CO}}}=\frac{\mathrm{M}_{\mathrm{B}_{\mathrm{CO}_{2}}}}{\dot{\mathrm{Q}}_{\mathrm{B}}} \frac{d \mathrm{P}_{\mathrm{B}_{\mathrm{CO}_{2}}}}{d t}-\frac{\mathrm{MR}_{\mathrm{B}_{\mathrm{CO}_{2}}}}{\mathrm{~K}_{\mathrm{CO}_{2}} \dot{\mathrm{Q}}_{\mathrm{B}}}+\mathrm{P}_{\mathrm{B}_{\mathrm{CO}_{2}}} .
$$

And under the steady state assumption:

$$
\frac{d \mathrm{P}_{\mathrm{B} \mathrm{O}_{2}}}{d t}=0
$$

We derive:

$$
\mathrm{P}_{\overline{\mathrm{a}}_{\mathrm{CO}_{2}}}=-\frac{\mathrm{MR}_{\mathrm{B}_{\mathrm{CO}_{2}}}}{\mathrm{~K}_{\mathrm{CO}_{2}} \dot{\mathrm{Q}}_{\mathrm{B}}}+\mathrm{P}_{\mathrm{B}_{\mathrm{CO}_{2}}} .
$$

By substituting this expression for $\mathrm{P}_{\overline{\mathrm{a}}_{\mathrm{CO}_{2}}}$ into the above equation for $\dot{\mathrm{V}}_{\mathrm{C}}$ yields:

$$
\dot{\mathrm{V}}_{\mathrm{C}}=\mathrm{G}_{\mathrm{C}}\left(\mathrm{P}_{\mathrm{B}_{\mathrm{CO}_{2}}}-\frac{\mathrm{MR}_{\mathrm{B}_{\mathrm{CO}}}}{\mathrm{K}_{\mathrm{CO}_{2}} \dot{\mathrm{Q}}_{\mathrm{B}}}-\mathrm{I}_{\mathrm{C}}\right)
$$

Introducing the delay to the peripheral control, time dependencies and summing the two drive components we arrive at:

$$
\begin{aligned}
\dot{\mathrm{V}}_{\mathrm{I}}=\mathrm{G}_{\mathrm{P}} \exp \left(-.05 \mathrm{P}_{\mathrm{O}_{2}}\left(t-\tau_{\mathrm{a}}\right)\right)\left(\mathrm{P}_{\mathrm{C}_{\mathrm{CO}_{2}}}\left(t-\tau_{\mathrm{a}}\right)-\mathrm{I}_{\mathrm{P}}\right) \\
+\mathrm{G}_{\mathrm{C}}\left(\mathrm{P}_{\mathrm{B}_{\mathrm{CO}_{2}}}(t)-\frac{\left.\mathrm{MR}_{\mathrm{B}_{\mathrm{CO}_{2}}}-\mathrm{I}_{\mathrm{C}}\right) .}{\mathrm{K}_{\mathrm{CO}_{2}} \dot{\mathrm{Q}}_{\mathrm{B}}}\right.
\end{aligned}
$$


Oxygen saturation $\mathrm{S}_{\mathrm{O}_{2}}$ is a measure of oxygen content (hence $\mathrm{P}_{\mathrm{a}_{2}}$ ) in the blood. $\mathrm{S}_{\mathrm{O}_{2}}$ reflects the percent of hemoglobin molecules fully bound with $\mathrm{O}_{2}$. The equation for $\mathrm{S}_{\mathrm{O}_{2}}$ is cited in [60]:

$$
\mathrm{S}_{\mathrm{O}_{2}}=100\left(1-2.4 \exp \left(-.05 \mathrm{P}_{\mathrm{a}_{\mathrm{O}_{2}}}\right)\right)
$$

To allow for a residual peripheral response at hyperoxia a small term is added to the control equation by rewriting it in the following way:

$$
\dot{\mathrm{V}}_{\mathrm{P}}=\mathrm{G}_{\mathrm{P}}\left(102.4-\mathrm{S}_{\mathrm{O}_{2}}\right)\left(\mathrm{P}_{\mathrm{a}_{\mathrm{CO}_{2}}}\left(t-\tau_{\mathrm{a}}\right)-\mathrm{I}_{\mathrm{P}}\right)
$$

Note that in this form the peripheral response depends on oxygen saturation. and the factor $G_{P}$ will be smaller by a factor of 100 . This form of the peripheral control is used in the simulations for adults, the form without residual errct is used for infants. With the parameter values given in the appendix the peripheral response represents $25 \%$ of the total controller response and the $\mathrm{CO}_{2}$ sensitivity translates to 2.2 liter $/ \mathrm{min} / \mathrm{mmHg}$.

Controller function $\dot{V}_{\text {I }}$ represents general ventilatory drive in liters/minute. Tidal volume or breath by breath simulation can be obtained by considering the details of a single breath. During inspiration the first segment of air is left-over exhaled air remaining in the dead space of the lungs (the branching tubes which do not exchange gases). This volume is approximately $150 \mathrm{ml}$ for an adult. Neither this air nor expired air provides the same volumes of $\mathrm{CO}_{2}$ and $\mathrm{O}_{2}$ compared to fresh air. Hence $\dot{\mathrm{V}}_{\mathrm{I}}$ will be replaced in the state equations by $\dot{V}_{\text {eff }}$ as follows. On the first segment of inspiration (until the stale air in the dead space has passed into the lungs) $\dot{V}_{\text {eff }}$ should be a reduced level of $\dot{V}_{\mathrm{I}}$. During the remaining segment of inspiration $\dot{\mathrm{V}}_{\text {eff }}$ should equal $\dot{\mathrm{V}}_{\mathrm{I}}$. Finally during expiration $\dot{V}_{\text {eff }}$ will again be a reduced level of $\dot{V}_{\mathrm{I}}$. In practice, we alter the value of EF in the state equations for $\mathrm{P}_{\mathrm{CO}_{2}}$ and $\mathrm{P}_{\mathrm{O}_{2}}$ to reduce $\dot{\mathrm{V}}_{\mathrm{I}}$. Furthermore, $\mathrm{M}_{\mathrm{L}_{\mathrm{CO}_{2}}}$ and $\mathrm{M}_{\mathrm{L}_{\mathrm{O}_{2}}}$ are varied during inspiration and expiration depending on $\dot{\mathrm{V}}_{\mathrm{I}}$ (see Khoo et al. [61] for details). The actual chemical drive in the model will be proportionally larger to force the flow of fresh air through the lung compartment during the fresh air phase of inspiration (a factor of about 2.5). A small alveolar-arterial oxygen gradient (A-a) $\mathrm{O}_{2}$ is assumed to account for ventilation/perfusion mismatch and a residual R-L shunt in adults [80]. Breath by breath calculations can be found as:

$$
\mathrm{V}_{\text {tidal }}=\mathrm{t}_{\mathrm{I}} \dot{\mathrm{V}}_{\mathrm{I}}
$$

where $\quad \mathrm{t}_{\mathrm{I}}=$ time of inspiration (around $1.5 \mathrm{sec}$ )

$\dot{\mathrm{V}}_{\mathrm{I}}=$ inspiration drive in liters per minute

6. Blood Flow and Variable Delay. Blood flow to various regions of the body depends on a large number of factors including cardiac output, blood pressure, crosssection of arteries and partial pressures of $\mathrm{CO}_{2}$ and $\mathrm{O}_{2}$ in the blood. Blood flow in various regions of the body depends on both central mechanisms of control and on local mechanisms in the region (see, e.g.,[101, 40] for details). Blood flow regulation is a very complicated phenomenon and the subject of ongoing research (see, e.g., [53] for an extensive cardiovascular model). Transport delays, in turn, depend on the blood flow rates to various areas. On first leaving the heart, arterial blood flow depends on cardiac output. As blood flow branches to special areas such as the brain, this flow rate becomes dependent also on local mechanisms of control. Cardiac output itself 
depends on the interaction of a number of factors including $\mathrm{Pa}_{\mathrm{CO}_{2}}$ and $\mathrm{Pa}_{\mathrm{O}_{2}}$ [101] Holding other factors constant, a relation between $\dot{\mathrm{Q}}, \mathrm{P}_{\mathrm{C}_{2}}$ and $\mathrm{Pa}_{\mathrm{O}_{2}}$ is given by Richardson et al. [101] and a model reflecting these relations is given by Finchman and Tehrani [28]. We have incorporated these factors into the model. Cerebral blood flow is controlled locally in the brain by restricting or expanding the arterial vessels. The degree of constriction depends on the levels of $\mathrm{Pa}_{\mathrm{CO}_{2}}$ and $\mathrm{Pa}_{\mathrm{O}_{2}}$ in the brain. This phenomenon has been described by Lambertsen [65] and a model reflecting the data given by Lambertsen has been developed by Khoo [55] and is a part of this model. To calculate the transport delay from the lung to the chemosensors in the brain we need first to calculate the delay involved in transporting from the lung to the branching of the carotid artery leading to the brain. Secondly, the delay involved from the carotid artery entrance to the peripheral sensors must be calculated. Thirdly, the delay from the peripheral sensors to the central sensor in the brain itself must be calculated. The former delay depends on $\dot{Q}$ and the volume of the arterial branch from lung to carotid while the latter delays depend on $\dot{\mathrm{Q}}_{\mathrm{B}}$ and the volumes of the vascular segments from the carotid artery to the peripheral sensor and from there to the central sensor in the brain. Data for the various volume segments are found in Table 4. Using the history of $\dot{\mathrm{Q}}$ and $\dot{\mathrm{Q}}_{\mathrm{B}}$ and the relevant volumes, the transport delays are found by integrating the blood flow rates backward in time until the volumes are filled. Similar calculations give the delay to the peripheral sensors in the carotid bodies.

7. Simulations of Human Respiratory Physiology. Simulations of various conditions are carried out using appropriate parameter values chosen to reflect these conditions. We present here simulations of the adult steady state and congestive heart condition using the parameter values given in [60]. These parameters and initial conditions are found in the various tables at the end of this paper. The delay times are calculated by integrating backward the blood flow rates until the volumes are reached for the arterial segments leading from the lung to the site of the sensory elements. The values used for these volumes are found in [36]. Numerical solutions are obtained using SNDDELM,a code developed by Lo and Jackiewicz [68] for the numerical solution of systems of neutral delay differential equations with state-dependent delays using Adams predictor-corrector methods. We are indebted to the authors for allowing us to use this robust code to perform all simulations reported in this paper.

7.1. Normal Awake Adult Case. Figures 5-7 represent the steady state levels for the system variables in a normal adult awake case. The simulated values for partial pressures,tidal volume and blood flow are consistent with the data presented in $[85,80,59,47]$.

7.2. Congestive Heart Condition. Figures 8-10 represent simulations using parameter values suggestive of the congestive heart condition. For this case, $\dot{Q}$ is reduced to one half the normal level and hence the transport delays are doubled. This causes instability in the system resulting in central apnea (CA) and periodic breathing as can be seen in Figure 9. Cheyne-Stokes respiration (CSR) is exhibited. Early studies [41, 96] suggested that excessive delay time might be the prime cause of (CSR). Current research suggests that a number of factors contribute to the phenomenon. For instance, it has been found that the application of continuous positive airway pressure (CPAP) acts to counter the onset of CSR [84]. Also, hypocapnia is an important factor in CSR in congestive heart failure and circulatory delay plays an important role in determining CSR-CA cycle length [83]. Excessive circulatory delay time certainly contributes to the "hunting phenomenon" first suggested by Douglas and Haldane to 


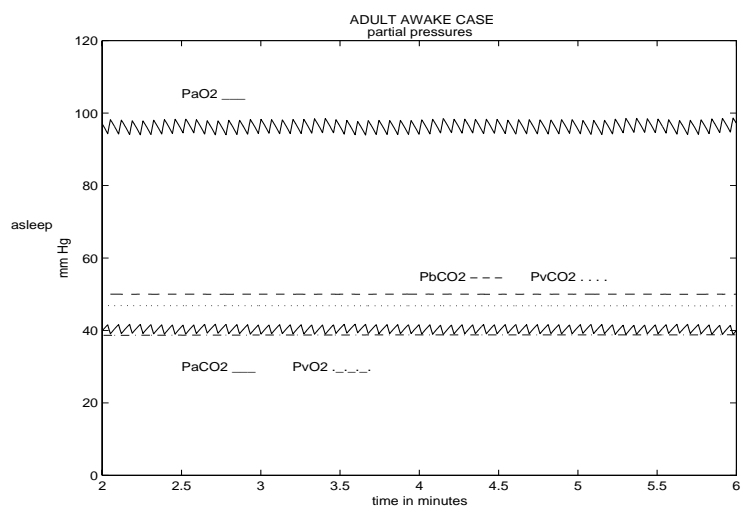

FIG. 5.

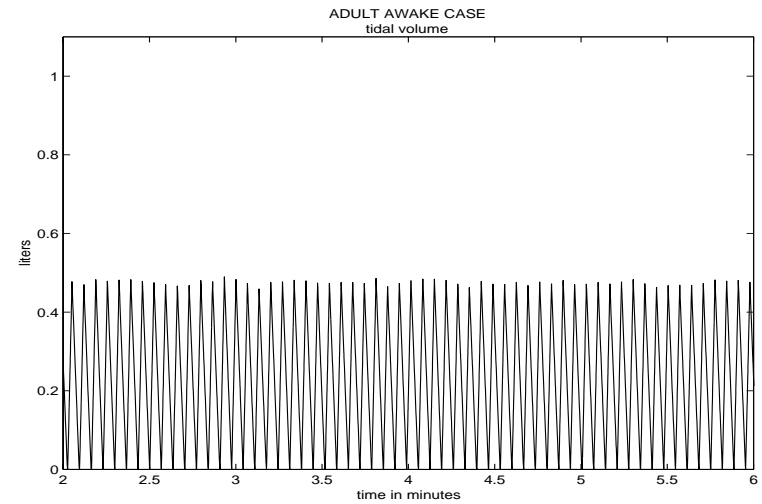

FIG. 6.

account for PB and CSR [58]. Simulations with the above model show that for certain values of controller gain, very long delay times may not produce oscillations but with other controller gain values such as used in the simulations in Figures 8-10 oscillations are produced.

\subsection{Modeling Sleep.}

7.3.1. Basic Sleep Condition. The sleep condition involves a number of different states and stages with different physiological profiles. As one passes from stage 1 sleep (S1) to stage 4 sleep (S4) the $\mathrm{CO}_{2}$ response curve shifts rightward, response to overall ventilatory drive diminishes and muscle resistance to the upper airways and other muscle groups related to breathing increases. These effects are referred to as loss of the "wakefulness stimulus" [99, 59]. Once stage 4 is reached the sleeper shifts between non rapid eye movement sleep (NREM) and rapid eye movement sleep (REM). These two states have significant physiological differences which affect the stability of the respiratory control system [15]. In 1991, Khoo [55] adapted the basic model to reflect the loss of wakefulness stimuli and model NREM sleep. The model equations reflecting these facts are:

$$
\dot{\mathrm{V}}_{\mathrm{S}}=\mathrm{G}_{\mathrm{w}}\left[\left[\dot{\mathrm{V}}_{\mathrm{I}}-\mathrm{S}_{\mathrm{w}}\right]\right]
$$




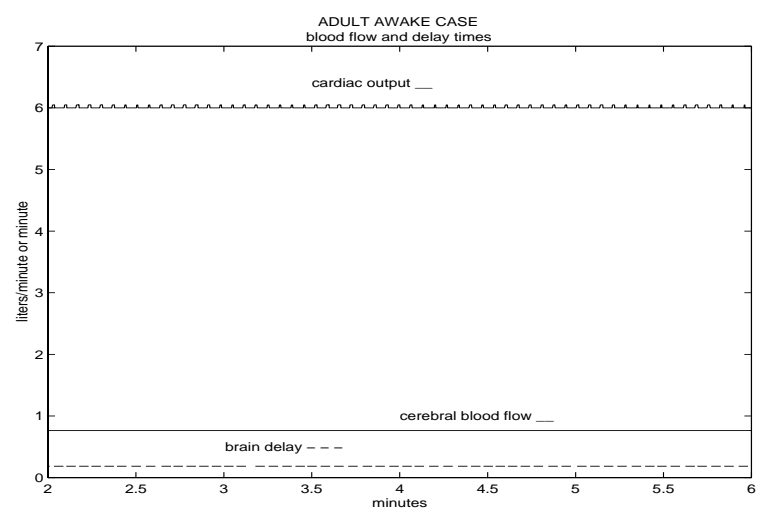

FIG. 7.

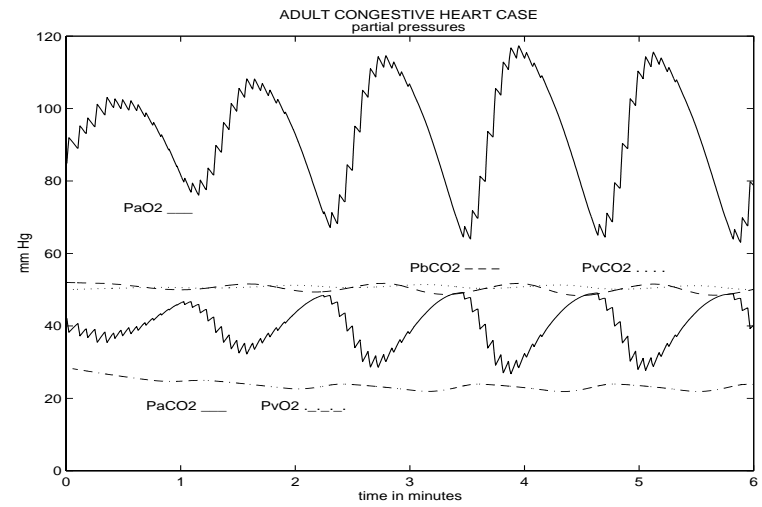

FIG. 8 .

where $\dot{V}_{S}$ is the effective drive during sleep, $G_{\mathrm{w}}$ is the slope of ventilatory drive, and $S_{\mathrm{w}}$ is the shift in ventilatory drive during sleep. Note that, $\mathrm{G}_{\mathrm{w}}$ and $\mathrm{S}_{\mathrm{w}}$ vary as one passes from stage 1 to stage 4 sleep as follows:

$$
\begin{aligned}
& \mathrm{G}_{\mathrm{w}}=1-0.4 \mathrm{E}, \\
& \mathrm{S}_{\mathrm{w}}=\mathrm{S}_{\mathrm{O}}(\mathrm{E} / 0.25) \text { for } 0 \leq E \leq 0.25, \\
& \mathrm{~S}_{\mathrm{w}}=\mathrm{S}_{\mathrm{O}} \text { for } .25 \leq E \leq 1.0 .
\end{aligned}
$$

Note also that the double brackets indicates that $\dot{V}_{\mathrm{S}}$ is greater than or equal to zero. Here, $\mathrm{E}$ is the ratio of elapsed time from the start of the sleep cycle to the time needed to transit from the awake to stage- 4 sleep, and $S_{O}$ is the maximal shift in ventilatory response (around $6 \mathrm{l} / \mathrm{min}$ ). Stage one sleep (S1) is assumed to begin when $\mathrm{E}=0.25$. The other stages occur as $\mathrm{E}$ varies from 0.25 to 1 where $\mathrm{S} 4$ begins. Thus the gain factor $G_{\mathrm{w}}$ reduces somoothly as one transits to $\mathrm{S} 4$ sleep while the maximal shift in $\mathrm{S}_{\mathrm{w}}$ is achieved by the start of S1 sleep. Metabolic rates are assumed to decrease linearly with depth of sleep, consistent with clinical data [94]. Arousal from sleep occurs if the chemical drive exceeds a level known as the arousal threshold. This occurs during extreme deviations in the levels of $\mathrm{Pa}_{\mathrm{CO}_{2}}$ and $\mathrm{Pa}_{\mathrm{O}_{2}}$ and has obvious survival value. In the model, this level is set at 15 liters per minute ventilatory drive. Other parameter 


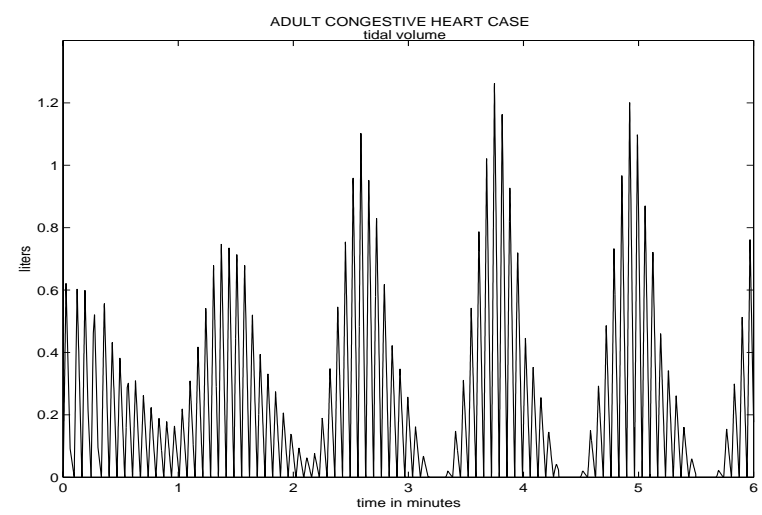

Fig. 9.

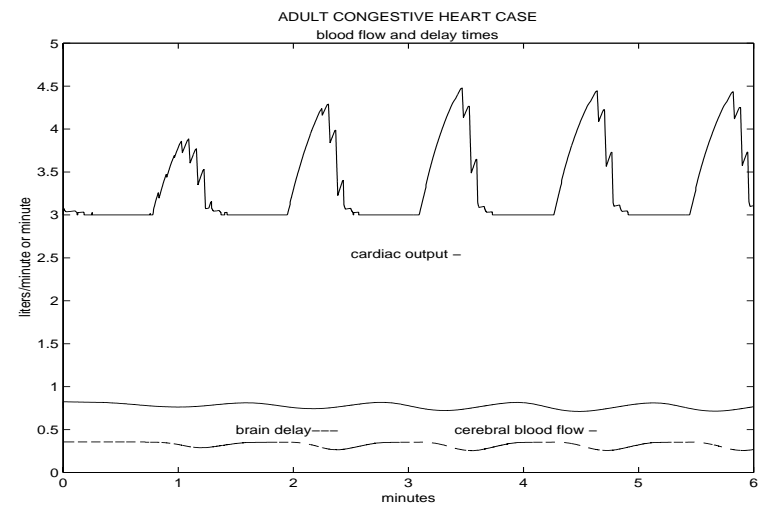

FIG. 10 .

values and the initial conditions are the nominal awake values. $\mathrm{P}_{\mathrm{CO}_{2}}$ level rises and $\mathrm{Pa}_{\mathrm{O}_{2}}$ falls [94] as one transits to stage 4 or slow wave sleep (SWS 4). Tidal volume may actualy rise during NREM sleep while breath frequency falls. The net effect is a decrease in minute ventilation of about $10 \%$. In these simulations breath frequency is held fixed and tidal volume reflects the decrease in minute ventilation. Simulations of the adult sleep state are given in Figures 11-15. Figure 11 and 12 model a smooth transition to stage 4 sleep with a slow $(180 \mathrm{sec}$.) transition to sleep. volume reflects the decrease in minute ventilation. Simulations of the adult sleep state are given in Figures 11-15. Figure 11 and 12 model a smooth transition to stage 4 sleep with a slow $(120 \mathrm{sec}$.) transition to sleep.

7.3.2. Sleep Apnea and PB. Apnea is the term used to describe cessation of breathing and has two forms: central apnea where there is a loss of controller drive, and obstructive apnea where a blockage of the airways results in cessation of breathing. If PB ventilatory drive oscillations grow large enough, the minimal phase of the cycle can result in loss of ventilatory drive and hence apnea (see Figure 9). This is one explanation for the origin of central apnea in PB. The causes for obstructive apnea are discussed in section 7.3.3. PB and apnea commonly occur during sleep. It has been observed that central apnea can lead to obstructive apnea during sleep [72]. The occurrence of PB and apnea during sleep is related to a number of changes 
which occur during sleep as described above in section 7.3.1. These effects include the right shift in the $\mathrm{CO}_{2}$ apneic threshold, effects on the central control gain and the reduction in the body's response to the ventilatory drive produced by the central and peripheral control signals. These effects are caused by chemical and neurological changes occuring in the body and brain as a result of the sleep state [99]. Apneas can constitute as much as 20-50\% of total cycle time of PB during sleep [72]. The phenomena just described have been modeled in several papers (see, for example, $[55,72,56])$.

Infants commonly experience apnea during sleep. The length of apneic spells in infants less than 6 months old is normally less than 10 seconds. Longer periods have clinical significance [46]. Periodic breathing and apnea have been linked to sudden infant death in many studies and is an ongoing topic of research [111].

PB occurs during both REM sleep and NREM sleep but the PB associated with NREM sleep is more regular with more or less constant breathing intervals and apneic periods [102]. PB in REM sleep is more disorganized. In infants 1 month old, $4 \%$ of sleep time is in some form of PB [109]. Apneas are more common during REM sleep and more often associated with bradychardia, but apnea and bradychardia may also be associated during NREM sleep [102]. Figures 13 - 15 represent the adult sleep case with a fast transition of 20 sec. to stage 1 sleep. As the transition to S4 occurs $G_{C}$ and $G_{P}$ are reduced to one half the normal $S 4$ level, a low controller gain value. Thus the control equation profile is significantly altered during this transition to $\mathrm{S} 4$ as compared to the transition in Figures 11-12. The result of these changes is that during transition to $\mathrm{S} 1$ a central apnea occurs producing disturbances in $\mathrm{Paco}_{2}$ and $\mathrm{Pa}_{\mathrm{O}_{2}}$ sufficient to force the chemical ventilatory drive past the arousal threshold. Recurring cycles of arousal/sleep transitions/apneas develop. Note that $\mathrm{Pa}_{\mathrm{CO}_{2}}$ rises and $\mathrm{S}_{\mathrm{O}_{2}}$ falls as reported in [94, 66].

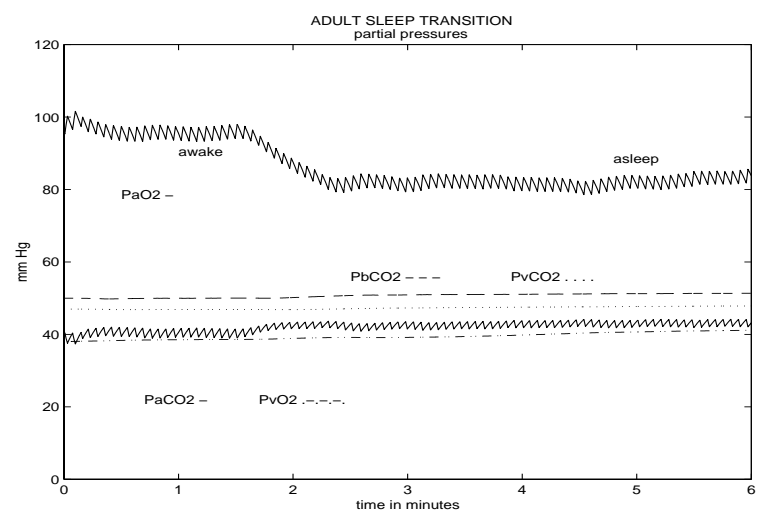

FIG. 11

7.3.3. Modeling Sleep Apnea. Periods of apnea and PB occur normally during sleep in infants and adults and can sometimes have serious medical consequences. One form of apnea is central apnea (CA) which occurs when ventilatory drive is lost or falls below a minimum threshold level. A second form is obstructive apnea (OA) which occurs when the upper airway collapses (loss of patency) blocking the flow of air to and from the lungs. In this case breathing movements are produced by the diaphragm but no airflow occurs through the upper airway. To maintain patency 


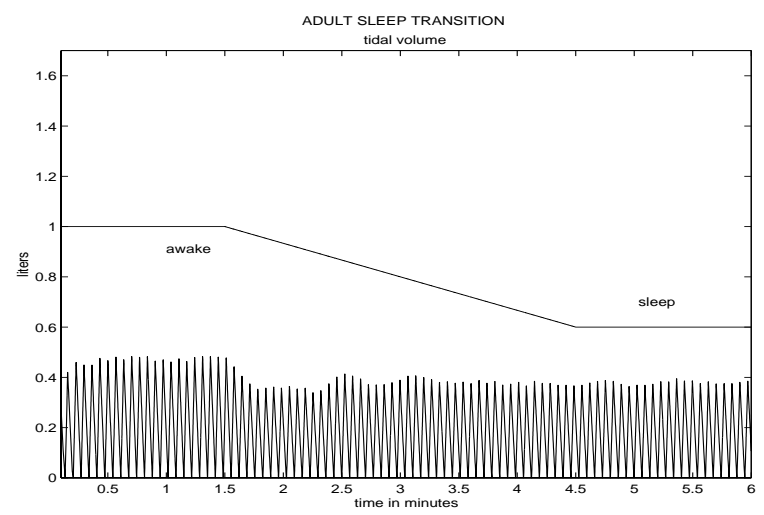

FIG. 12 .

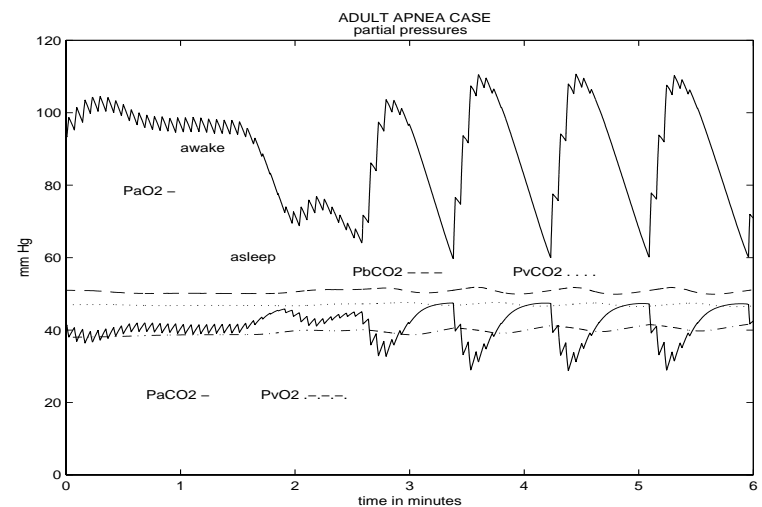

FIG. 13

there are muscle groups which act to dilate the upper airway path and maintain a free airflow from the nose through the nasopharynx, pharynx and larynx to the lower airway or trachea. The ventilatory control system stimulates both the respiratory muscles in the diaphragm and the muscle groups dilating the upper airway. This is necessary since the diaphragm acts to expand the lungs resulting in a negative air pressure or vaccuum which pulls air into the lungs. This negative pressure also acts to pull the upper airway closed. The dilating muscles oppose this pressure.

During the awake stage, the general effects of the awake condition and the interaction of neurological, chemo-ventilatory drive and conscious control remove any possibility for OA to occur. However, during sleep a number of factors change. In the first place, the only control of respiration is due to the chemoreceptor system. Secondly, as discussed above (section 7.3.1), the transition to sleep affects the response of the respiratory control system to the signals produced by the chemoreceptors. This effect is referred to as removal of the "wakefulness stimulus". Several models have been developed to describe the phenomenon of OA. Some research indicates that the effect of withdrawal of the wakefulness stimulus on the diaphragm and upper airway muscles are disproportionate (affecting the upper airway more) see, e.g., [117, 72, 125, 32]. In this case, the negative pressure due to the effect of the ventilatory drive on the thoraxic muscles may overcome the dilational force of the airway muscles resulting 


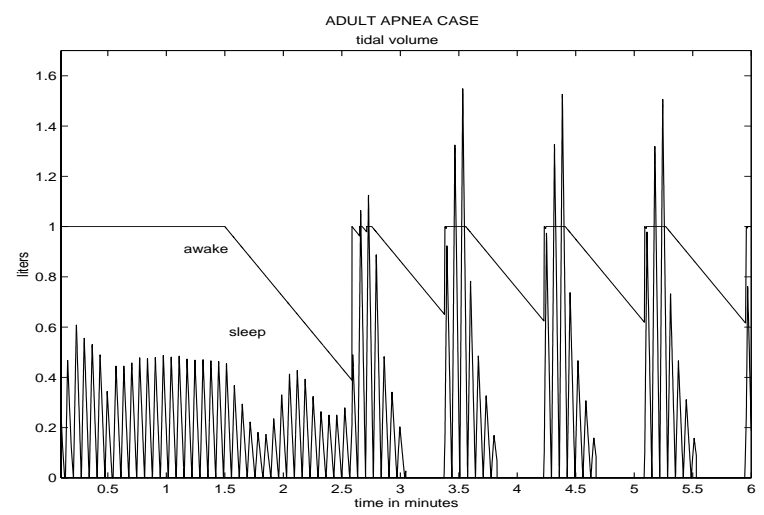

FIG. 14 .

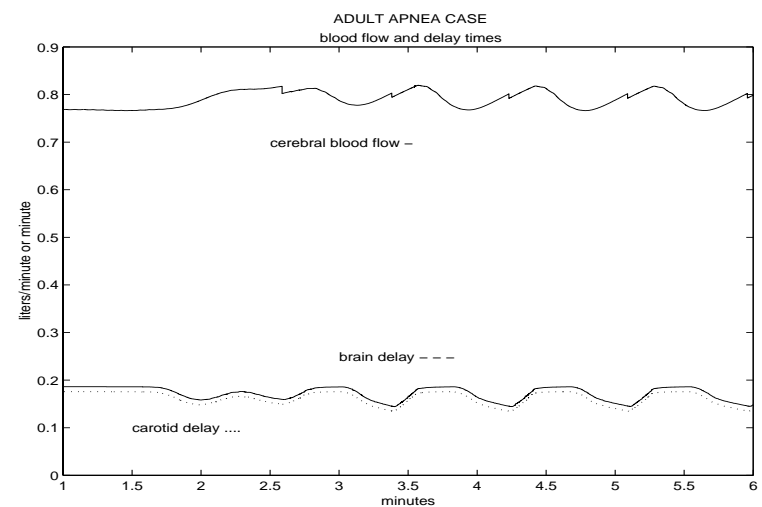

FIG. 15.

in upper airway collapse $[117,14]$. It is also possible that the sleep state produces different response thresholds in the various muscle groups which results in disproportionate response to ventilatory drive [14]. Other research indicates that the reduction in muscle tone and effectiveness is proportional for all muscle groups involved in respiration and therefore no such antagonism between the diaphragm and upper airway muscles would account for OA [2,21, 124]. In this case OA may be produced by a nonexcessive reduction in upper airway muscle activity during sleep acting on a geometrically small airway lumen [7].

Due to the effect of withdrawal of the wakefulness stimulus during sleep ventilatory drive does not need to reach zero before air flow ceases. Sufficiently low ventilatory drive will result in loss of respiratory muscular response and central apnea (CA). The cessation of breathing may also cause the upper airway to collapse. Ventilatory drive must rise to a high level to reopen the airway [15, 91]. Khoo modeled this form of apnea (mixed apnea) by reducing to zero the effective ventilatory drive whenever this drive reaches a level too low to maintain upper airway patency. It is assumed that ventilation does not begin again until arousal occurs [59]. In this case the original cessation in breathing due to low drive may be viewed as a central apnea which causes collapse of the airway. Ventilatory drive (above the minimum level) will not be able to reopen the airway until arousal occurs and this may be viewed as OA. 
This model for the development of OA captures the salient features of low ventilatory drive (central apnea) producing obstruction which is not terminated until arousal [7] and the restoration of the wakefulness stimulus restores patency and uppper airway muscle efficacy. Central apnea may also be produced during the transition to sleep if the decrease in nonmetabolic respiratory stimuli will not allow ventilatory muscle activation until $\mathrm{P}_{\mathrm{CO}_{2}}$ rises to the higher sleep set point which then produces ventilatory drive high enough to activate ventilatory muscles [6].

In this model we consider only the withdrawal of the wakefulness stimulus sufficient to produce transient reduction in ventilatory drive past a minimal threshold. This will be interpreted as a central apnea. We will assume that this apneic episode will terminate only with arousal. Arousal will be triggered by the chemical ventilatory stimulus rising above an arousal threshold level. Arousal will reset the control mechanism to its awake parameter values. A new transition to sleep will then commence.

Apnea in infants is a more complicated phenomenon. Central apnea is common while obstructive apnea is more rare and includes a condition of partial airway collpase. Little is known about the mechanisms which terminate an apneic episode of either kind. However, arousal is an important factor and is a protective response to dangerous conditions during sleep [30]. Definitions of arousal are not fully standardized and include EEG arousal,movement arousal and behavioral arousal. Not all apneas end through arousal [31] however one important study of infants with increased upper airway resistance exhibited an abnormal number of EEG arousals [39]. Miniarousals defined by Hoppenbrouwers as movement after apnea [49] have been reported in preterm and fullterm infants [49]. Miniarousals which prevent prolonged OA seem to occur in infants [31]. Litle is definitively known about the causes for and termination of apnea in infants.

We will model the apneic mechanism as a black box. If ventilatory drive falls below a minimum threshold breathing will terminate. This will signify a central apnea. Breathing will not begin again until the chemical stimulus rises to a sufficielntly high level which will be termed the arousal threshold. This will trigger effective arousal and a resetting of the awake ventilatory control parameters. In this study we consider the effects of arousal and recycling the sleep transition process on respiratory stability.

\subsection{Modeling Infant Respiration.}

7.4.1. Basic Considerations. In modeling the respiratory processes of infants we use allometric scaling for physical parameters. The nominal parameter values in the tables are for a typical $70 \mathrm{~kg}$ adult and a $3.2 \mathrm{~kg}$ infant at birth. Weight scaling for a 3-4 month old infant can be found in [119]. Comparative data for physical parameters can be found in [85, 1]. Initial partial pressure data can be found in $[103,81,74]$ and control system parameters are taken from $[113,86,87,100]$. The dissociation parameters for $\mathrm{O}_{2}$ vary during the early developmental stages for infants as fetal hemoglobin is replaced by adult hemoglobin. This transition is completed during the first 6 months after which the $\mathrm{O}_{2}$ dissociation curve and loading characteristics approach that of adults [20]. The so-called paradoxical response to hypoxia disappears after the first two weeks [34]. Significant functional closure of the Foramen Ovale and the Ductus Arteriosus are assumed $[79,75,1]$ with a remaining $5 \%$ shunt of blood from the systemic venous return to systemic arterial blood flow assumed. There is an overall drop in $\mathrm{P}_{\mathrm{O}_{2}}$ between the level $\mathrm{P}_{\mathrm{A}_{\mathrm{O}_{2}}}$ in the alveoli and the $\mathrm{P}_{\mathrm{O}_{2}}$ level entering the tissue compartment. Part of this drop is due to the $\mathrm{R}_{\mathrm{L}}$ shunt and part is due to ventilation/perfusion mismatch in the lungs denoted as $D_{\text {A-cap }}$ [85]. Since 
the $R_{\mathrm{L}}$ shunt for infants is larger than for adults it is not appropriate to assume that $\mathrm{P}_{\mathrm{A}_{2}}$ is equal to $\mathrm{P}_{\mathrm{O}_{2}}$. From this point on $\mathrm{P}_{\mathrm{O}_{2}}$ will represent the partial pressure of $\mathrm{O}_{2}$ leaving the lung capillary system. The equations relating the state variable $\mathrm{Pa}_{\mathrm{O}_{2}}$ and the partial presssure of $\mathrm{O}_{2}$ entering the tissue compartment and carotid sensors will now be discussed. The blood coming from the lungs (rich in $\mathrm{O}_{2}$ ) and the blood shunted around the lungs (low in $\mathrm{O}_{2}$ ) are remixed resulting in a lower concentration of $\mathrm{O}_{2}$ than is found in the blood leaving the lungs. The equation reflecting this is as follows.

$$
\mathrm{C}_{\mathrm{am}_{\mathrm{O}_{2}}}=\alpha \mathrm{C}_{\mathrm{V}_{\mathrm{O}_{2}}}+(1-\alpha) \mathrm{C}_{\mathrm{a}_{\mathrm{O}_{2}}},
$$

where

$$
\begin{aligned}
& \mathrm{C}_{\mathrm{am}_{\mathrm{O}_{2}}}=\text { mixed concentration of } \mathrm{O}_{2} \text { from shunted blood and lungs } \\
& \mathrm{C}_{\mathrm{a}_{\mathrm{O}_{2}}}=\text { concentration of } \mathrm{O}_{2} \text { from the pulmonary venous system } \\
& \mathrm{C}_{\mathrm{a}_{\mathrm{O}_{2}}}=\text { concentration of } \mathrm{O}_{2} \text { from the shunted venous return } \\
& \alpha=\text { percent of shunted blood. }
\end{aligned}
$$

$\mathrm{P}_{\mathrm{am}_{\mathrm{O}_{2}}}$ (for mixed $\mathrm{O}_{2}$ arterial pressure) is calculated using the dissociation laws and will be used as input to the equation for the tissue compartment and the peripheral control equation. Figure 4 illustrates these facts. The equation for $\mathrm{P}_{\mathrm{V}_{\mathrm{O}_{2}}}$ is thus given as:

$$
\frac{d \mathrm{P}_{\mathrm{V}_{\mathrm{O}_{2}}}(t)}{d t}=\frac{\dot{\mathrm{Q}}_{\mathrm{T}}\left[\mathrm{m}_{\mathrm{a}} \mathrm{P}_{\mathrm{am}_{\mathrm{O}_{2}}}\left(t-\tau_{\mathrm{T}}\right)-\mathrm{m}_{\mathrm{v}} \mathrm{P}_{\mathrm{V}_{\mathrm{O}_{2}}}(t)+\mathrm{B}_{\mathrm{a}}-\mathrm{B}_{\mathrm{v}}\right]-\mathrm{MR}_{\mathrm{T}_{\mathrm{O}_{2}}}}{\mathrm{M}_{\mathrm{T}_{\mathrm{O}_{2}}} \mathrm{~m}_{\mathrm{v}}}
$$

The blood flow $\dot{\mathrm{Q}}$ to the lungs is reduced by the shunt factor $(1-\alpha)$ so that the equation for lung $\mathrm{P}_{\mathrm{O}_{2}}$ becomes:

$$
\begin{gathered}
\frac{d \mathrm{P}_{\mathrm{O}_{2}}(t)}{d t}=\frac{863(1-\alpha) \dot{\mathrm{Q}}\left[\mathrm{m}_{\mathrm{v}} \mathrm{P}_{\mathrm{V}_{\mathrm{O}_{2}}}\left(t-\tau_{\mathrm{v}}\right)-\mathrm{m}_{\mathrm{a}} \mathrm{P}_{\mathrm{a}_{\mathrm{O}_{2}}}(t)+\mathrm{B}_{\mathrm{v}}-\mathrm{B}_{\mathrm{a}}\right]}{\mathrm{M}_{\mathrm{L}_{\mathrm{O}_{2}}}} \\
+\frac{\mathrm{EFV} \dot{\mathrm{A}}_{\mathrm{A}}\left[\mathrm{P}_{\mathrm{I}_{\mathrm{O}_{2}}}-\mathrm{P}_{\mathrm{a}_{\mathrm{O}_{2}}}(t)\right]}{\mathrm{M}_{\mathrm{L}_{\mathrm{O}_{2}}}},
\end{gathered}
$$

Transport delay time for the shunted venous return to the arterial side of the tissue compartment where the concentrations are mixed are estimated in the tables. Due to insufficient data relating $\mathrm{Pa}_{\mathrm{CO}_{2}}$ and $\mathrm{Pa}_{\mathrm{O}_{2}}$ to $\dot{\mathrm{Q}}$ we assume $\dot{\mathrm{Q}}$ to be constant.

There is also an alveolar-capillary gradient $\mathrm{D}_{\mathrm{A} \text {-cap }}$ for $\mathrm{P}_{\mathrm{O}_{2}}[100,63]$ which is caused mainly by ventilation/perfusion mismatch [85, 105]. The values used are taken from $[85,100,113]$. There is little alveolar-arterial $\mathrm{CO}_{2}$ difference $[85,105]$ so that we still assume the relationship $\mathrm{P}_{\mathrm{ACO}_{2}}=\mathrm{PaCO}_{\mathrm{CO}_{2}}$.

The $\mathrm{O}_{2}$ dissociation curve changes during infancy and the values for a $3-4$ month old infant are taken from $[100,20]$. Dissociation parameters for $\mathrm{CO}_{2}$ are assumed the same as for adults $[100,34]$.

Normal and abnormal profiles of infant breathing patterns can be compared with those given by Rigato and Brady [103] and Hathorn [44, 45]. Excellent sources discussing infant physiology can be found in [105, 11, 110, 95, 20, 29, 81, 3, 73]. In Figures 16-18 note that the first segments of the graphs represent the simulated awake infant 
steady state values. These values are also give in Table 12 . We simulate a $6.0 \mathrm{~kg}$ infant around 4 month of age. $\mathrm{Pa}_{\mathrm{CO}_{2}}$ levels are somewhat lower for infants at 4 months than at birth and $\mathrm{Pa}_{\mathrm{O}_{2}}$ is higher. The simulated values are consistent with data given in $[50,81,110]$. The calculated tidal volume and minute ventilation is consistent for a four month old infant $(6 \mathrm{~kg})$ as reported in in [29, 85]. A crosscheck of the simulated values for $\mathrm{PaCO}_{\mathrm{CO}_{2}}$ and $\mathrm{Pa}_{\mathrm{O}_{2}}$ can be given by calculating $\mathrm{P}_{\mathrm{A}_{2}}$ two ways. From the equation given in [47] we have:

where

$$
\mathrm{P}_{\mathrm{AO}_{2}}=\mathrm{P}_{\mathrm{I}_{\mathrm{O}_{2}}}-\frac{\mathrm{P}_{\mathrm{CO}_{2}}}{\mathrm{RQ}}
$$

$$
\begin{aligned}
& \mathrm{RQ}=\text { respiratory quotient (given in the tables) } \\
& \mathrm{P}_{\mathrm{O}_{\mathrm{O}_{2}}}=\text { partial pressure of atmospheric } \mathrm{O}_{2} \\
& \mathrm{P}_{\mathrm{A}_{\mathrm{O}_{2}}}=\text { partial pressure of alveoli } \mathrm{O}_{2} \\
& \mathrm{P}_{\mathrm{a}_{\mathrm{CO}_{2}}}=\text { partial pressure of alveoli } \mathrm{CO}_{2}
\end{aligned}
$$

Also, $\mathrm{P}_{\mathrm{A}_{\mathrm{O}_{2}}}$ is also given as:

where

$$
\mathrm{P}_{\mathrm{AO}_{2}}=\mathrm{P}_{\mathrm{O}_{2}}+\mathrm{D}_{\mathrm{A}-\mathrm{cap}}
$$

$$
\begin{aligned}
& \mathrm{P}_{\mathrm{O}_{2}}=\text { partial pressure of } \mathrm{O}_{2} \text { leaving the capillaries } \\
& \mathrm{D}_{\mathrm{A} \text {-cap }}=\text { alveolar-capillary } \mathrm{P}_{\mathrm{O}_{2}} \text { gradient (from the tables) }
\end{aligned}
$$

Using values for $\mathrm{P}_{\mathrm{O}_{2}}$ taken from the simulation produces a $\mathrm{P}_{\mathrm{A}_{\mathrm{O}_{2}}}$ level consistent with those estimated from the RQ formula above which depends on $\mathrm{Pa}_{\mathrm{CO}_{2}}$. Note that for a four month old, the lower $\mathrm{P}_{\mathrm{CO}_{2}}$ level implies a higher $\mathrm{P}_{\mathrm{AO}_{2}}$.

7.4.2. Modeling the Infant Sleep State. The organization of sleep state patterns in the newborn is not completed before the age of 3 months. During the first few weeks after birth, the classic sleep states of REM and NREM sleep cannot be easily identified but after approximately 3 months, sleep begins with NREM sleep [89]. From that time on sleep patterns are more closely related to adult patterns [66, 89]. The physiological changes accompanying REM sleep are more complicated than NREM sleep and are not addressed in this model. For infants, as for adults, the transition from the awake state to sleep state results in changes in the response to overall ventilatory drive and muscle resistance to the upper airways and other muscle groups related to breathing $[46,102,66,123] . \mathrm{Pa}_{\mathrm{CO}_{2}}$ rises $2-4 \mathrm{~mm} \mathrm{Hg}$ as the infant transitions to stage 4 sleep and $\mathrm{O}_{2}$ saturation falls [50, 9]. Data on infant state variables is collected mostly during sleep [10]. $\mathrm{P}_{\mathrm{O}_{2}}$ values are somewhat higher and $\mathrm{Pa}_{\mathrm{CO}_{2}}$ levels somewhat lower for the awake infant [81]. The values for $\mathrm{Pa}_{\mathrm{O}_{2}}$ are reduced and values for $\mathrm{Pa}_{\mathrm{CO}_{2}}$ are increased during transition to stage 4 sleep (SWS 4) as is the case for adults (although not as much change)] [81]. We simulate a 4 month old infant matured enough so that NREM sleep normally precedes REM sleep during transitions from awake to sleep states. We model only the NREM stage. Minute ventilation depends on both tidal volume and breathing frequency. The relationships between frequency, tidal volume and blood gas levels are complex and in these simulations we hold the frequency constant so that tidal volume will reflect minute ventilation. Arterial blood gas data can only be obtained with an indwelling arterial catheter, which is not done except in exceptional cases. For general study, estimates can be made using end-tidal gas composition, and transcutaneous measurements. In general, transcutaneous $\mathrm{O}_{2}$ measurements aren't completely accurate, but can show trends [3] 
and $\mathrm{CO}_{2}$ measurements are corrected for changes in metabolism and other factors at the site of measurement. See, e.g, $[106,50]$ for discussion. The simulated values are well within the ranges presented in $[106,50,88,81]$. Figures $16-18$ refer to a sleep transition with no arousals. $\mathrm{P}_{\mathrm{CO}_{2}}$ and $\mathrm{P}_{\mathrm{B}_{\mathrm{CO}_{2}}}$ rise, while $\mathrm{S}_{\mathrm{O}_{2}}$ and minute ventilation fall. This is consistent with clinical observation [94, 30, 66]. Transition time to stage 4 sleep is slow enough and the shift in the operating point for $\dot{V}_{\mathrm{I}}$ is small enough so that the disturbances in $\mathrm{Pa}_{\mathrm{CO}_{2}}$ and $\mathrm{Pa}_{\mathrm{O}_{2}}$ do not produce instabilities in the system sufficient to cause apnea or arousal. The $2.9 \mathrm{~mm} \mathrm{Hg}$ change in $\mathrm{Pa}_{\mathrm{CO}_{2}}$ is consistent with data given in $[106,50]$ and the small decrease in $\mathrm{Pa}_{\mathrm{O}_{2}}$ falls between the values found [81] and [50]. In fact, after transition to sleep $\mathrm{Pa}_{\mathrm{O}_{2}}$ dips to a level consistent with data found in [81] and slowly recovers to the values closer to those found in [50]. Oxygen saturation falls by $2 \%$ consistent with the values found in [9]. Tidal volume is found to drop by about $10 \%$. A smaller drop in tidal volume can be produced by assuming a smaller drop in metabolic rates than is assumed here $(12 \%)$.

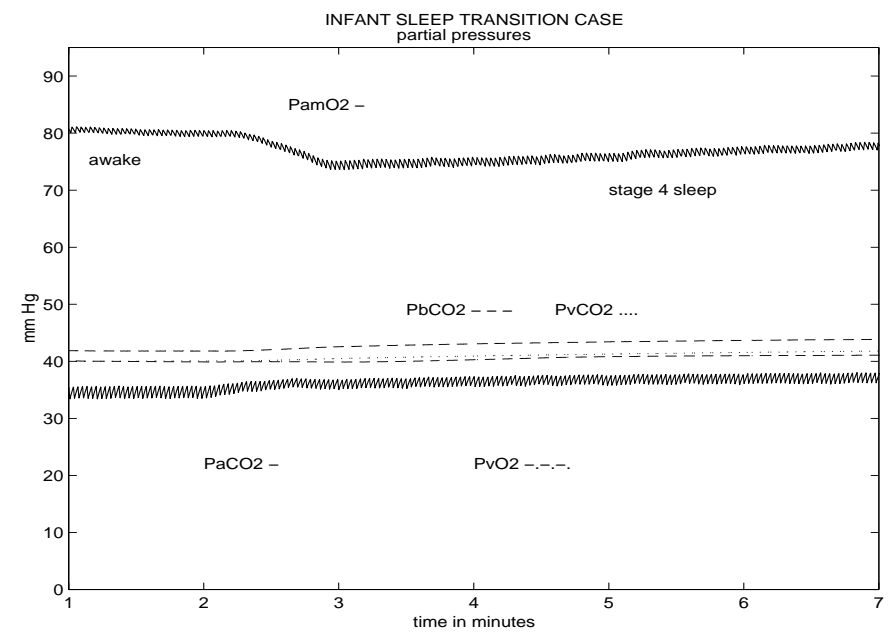

FIG. 16.

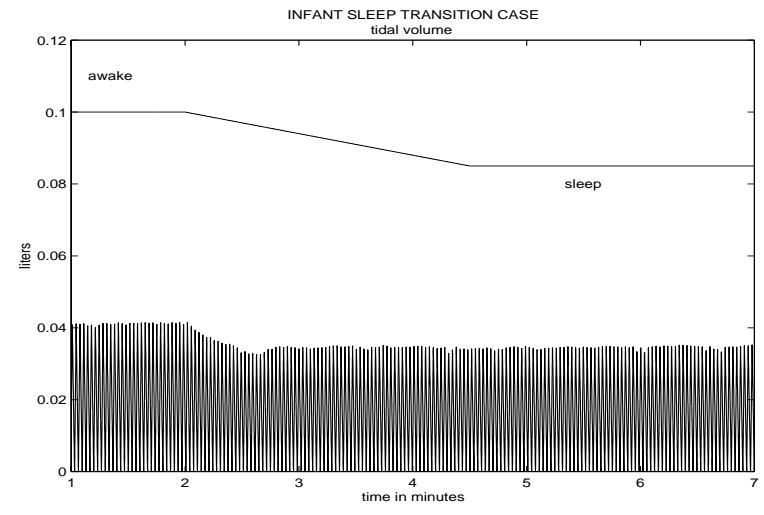

FIG. 17.

Figures 19-21 refer to a sleeping infant with arousal periods. In the figures for 


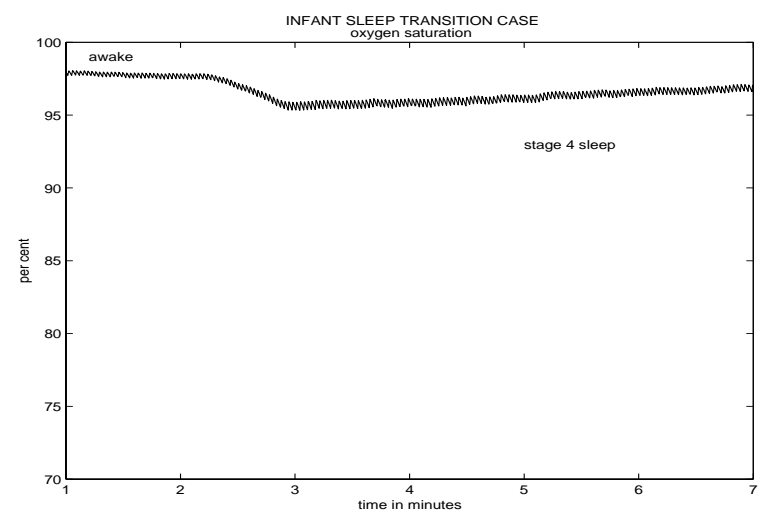

Fig. 18 .

tidal volume a scaled graph of $\mathrm{G}_{\mathrm{W}}$ is included to indicate the transitions from awake to sleep. Arousals can occur for various reasons including an increase in chemical drive past the arousal threshold level. For this case the $\mathrm{S} 1$ transition time is 20 seconds but the effect of withdrawal of the awake stimulus is assumed to occur during the first 12 seconds. Thus an abrupt shift in the operating point occurs. Furthermore, the maximal shift $S_{O}$ is higher than in the case of a smooth transition (about three fifths of the awake ventilatory drive). The level of control gain is also reduced at $\mathrm{S} 4$ to two thirds the normal level at S4. A lower arousal threshold is also assumed (see Table 16). The reduced arousal threshold and quick shift in the operating profile of the control equation and the subsequent disturbances to $\mathrm{Pa}_{\mathrm{CO}_{2}}$ and $\mathrm{P}_{\mathrm{O}_{2}}$ are sufficient to produce increases in ventilatory drive large enough to produce arousal. The degree of disturbance produces a train of sleep/arousal cycles. The oscillations in the partial pressures of $\mathrm{P}_{\mathrm{a}_{2}}$ and $\mathrm{P}_{\mathrm{O}_{2}}$ reflect these transitions from awake to sleep. During the initial transition ventilatory drive falls to the minimum threshold level needed to sustain breathing and an apnea occurs.

Figures 22-24 reflect apnea due

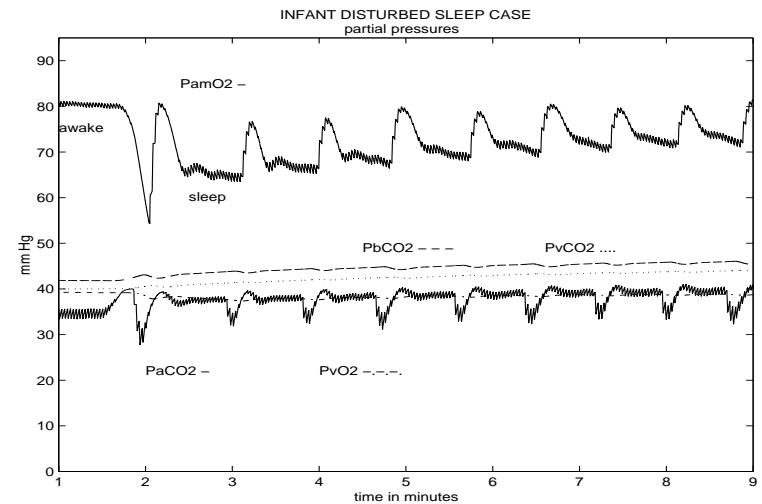

FIG. 19.

to ventilatory drive dropping to a level sufficiently low such that respiratory muscle response is absent and a central apneic episode begins. A fast transition time to the sleep state and increased maximal shift $S_{O}$ (nearly equal to the awake ventilatory drive [59]) and an increase in arousal threshold produces this case. See Table 16. The 


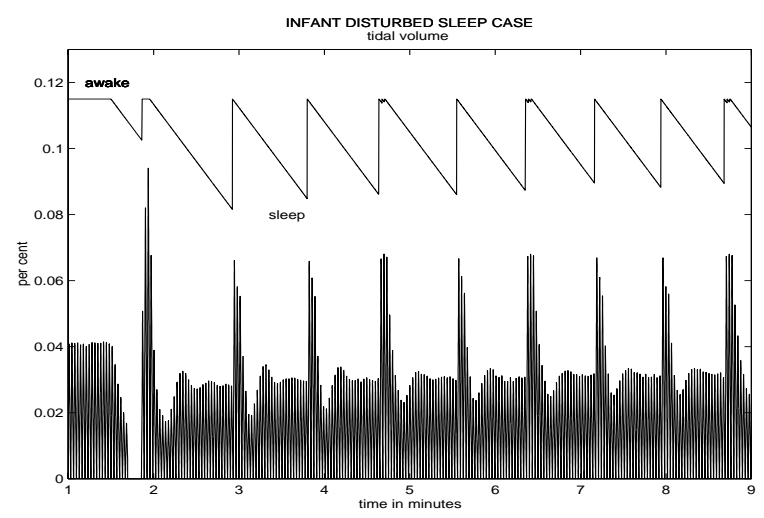

FIG. 20.

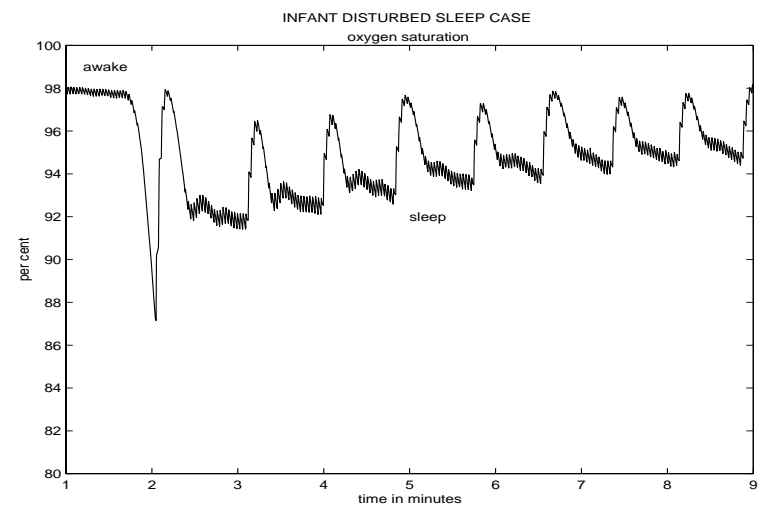

Fig. 21.

resulting apnea causes ventilatory drive to rise until arousal occurs. The disturbance to blood gas levels is sufficient to produce new cycles of apnea. The maximum levels of $\mathrm{Pa}_{\mathrm{CO}_{2}}$ are consistent with levels producing arousals as reported in [30]. The minimum $\mathrm{S}_{\mathrm{O}_{2}}$ levels lie in the hypoxic region as defined by [116]. The apneic cycles eventually disappear as the system slowly moves toward the steady state levels. In this case disturbed sleep cycles resume.

As mentioned previously, infants commonly experience apnea during sleep. In full term infants, periods of apnea less than $10 \mathrm{sec}$. are considered normal. Apneas longer than this are unusual according to [24] and clinically important if the apneas approach 20 seconds. Such episodes are most common in premature infants [97, 46]. The mean number of apneas for a three minute period is reported in one paper to range from 3 to 9 episodes [27]. These patterns vary with age, sleep state and the duration of the sleep period. OA occurs mostly in the form of mixed apneas [76] where ventilatory drive falls to zero or at least to a level so low that upper airway patency cannot be maintained. Sudden infant death syndrome or SIDS, a term coined only in 1969, has been anecdotally described since medieval times. It denotes the occurrence of death in a new born (less than one year in age) probably during sleep while unattended and with no discernible cause. A salient feature of SIDS (indeed one of its defining features among childhood disease) is that there are virtually no cases before week one and then 


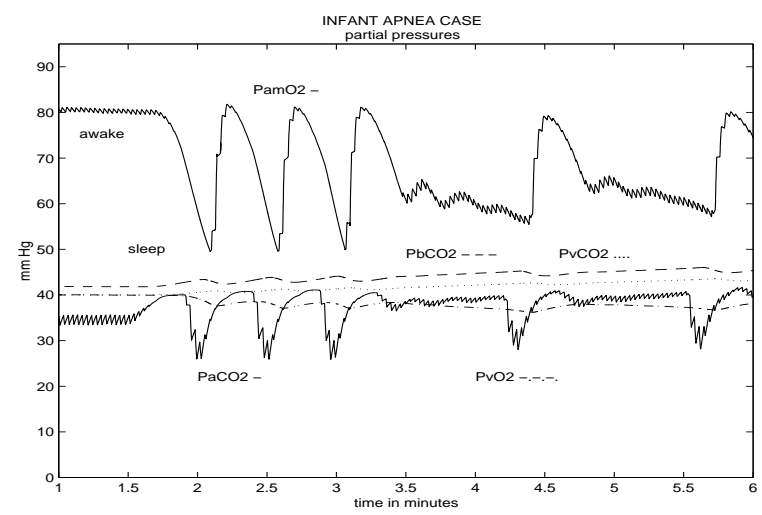

Fig. 22 .

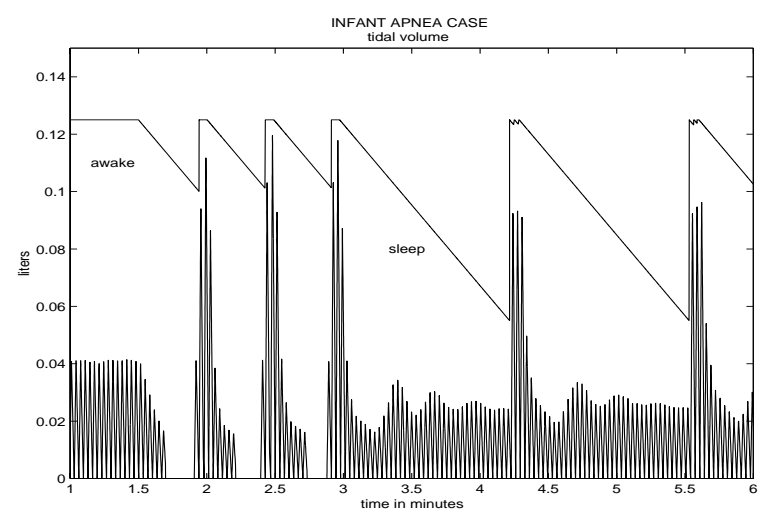

Fig. 23

the rate of occurrence increases smoothly until week 12 and then slowly declines to minimal rates after week 36 . The incidence of SIDS in the U.S. is 2 to 3 deaths per thousand live births for a total of between 7 to 10 thousand total deaths per year. This rate is remarkably stable over time. Recent appeals to have infants sleep on their back or side has reduced the incidence of SIDS. Though the total incidence is low it represents one of the most common causes of death for infants whose age is between one week and 1 year old [115]. It is not clear whether there is a single factor or a mix of factors producing the syndrome. Ultimately, death results from cardiac arrest but there is no consensus as to the precipitating cause of this cardiac arrest. It may be that cardiac failure is the actual cause of death or it may be that respiratory failure produces heart failure [93]. Periodic breathing and apnea have been linked to SIDS in many studies [109, 120, 38, 54]. Certainly, during sleep, PB occurs in children more often than in adults, and prolonged sleep apnea and PB are associated with infants. Preterm infants are much more susceptible to apneic episodes than other infants [64], [109]. While apneic episodes in infants are generally central (CA) and obstructive apnea $(\mathrm{OA})$ is relatively rare, significantly more obstructive apneas $(\mathrm{OA})$ have been observed in connection with SIDS victims and near miss SIDS infants [46, 26, 115]. It may be that $\mathrm{OA}$ is precipitated by a central apneic episode (such a situation is termed mixed apnea) $[38,114]$. The number of infants with $\mathrm{OA}$ and the number of obstructive 


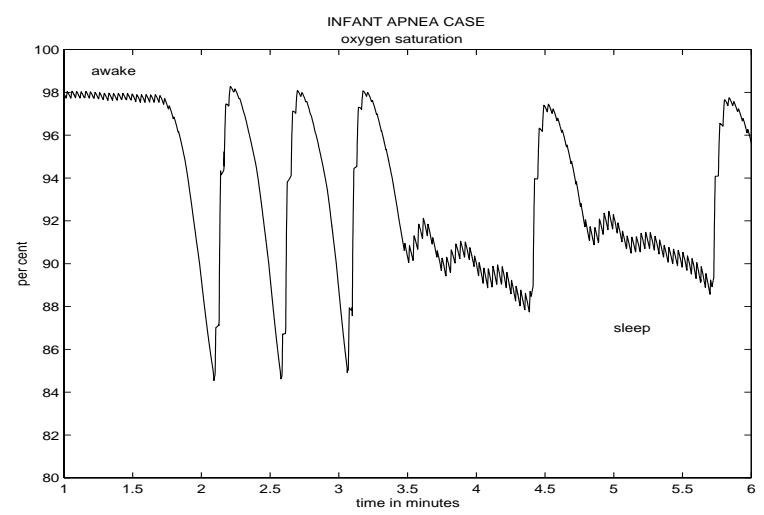

Fig. 24 .

apneas per infant were higher in future SID victims, as was the frequency, mean and maximal duration of central apneas of 3 to $10 \mathrm{sec}$. [108]. Apnea is often terminated by some form of arousal and thus the arousal mechanisms plays an important role in maintaining normal breathing during sleep. The mechanism for apnea as presented here allows for the possible interpretation of apneic episodes as either $\mathrm{CA}$ or $\mathrm{OA}$. The anatomical structure of the upper airway and the dilating muscles that act to maintain patency play a critical role in the occurence of OA and infants exhibiting heightened resistance to airflow will be at greater risk for OA should there be any disruption of the arousal mechanisms during sleep (including sleep fragmentation caused by repetitive arousals) [39]. Large swings in $\mathrm{Pa}_{\mathrm{O}_{2}}$ levels has been associated with infant groups at risk for SIDS [106].

Using the definitions for hypoxia given in [116], Figures 25 - 27 exhibit moderate to severe hypoxia at high arousal threshold and large shift in the ventilatory drive operating point. Cycles of disturbed sleep resume as in the previous case. Apnea length approaches levels considered medically significant. The number of apneas per minute is larger than was found in [106] but consistent with [27]. As arousal threshold is increased the length of apnea increases and the $\mathrm{O}_{2}$ saturation is reduced. For arousal threshold $10 \%$ below nominal, apnea occurs but is of short duration and $\mathrm{O}_{2}$ saturation reduction is moderate. When arousal threshold is increased by $25 \%$ apneic periods are in the range of 15 seconds and $\mathrm{O}_{2}$ saturation decreases to levels of significant hypoxia as defined in [116]. See Table 16 for comparisons. As seen below, the number of apneas per minute can be reduced by assuming a longer aroused period. This also acts to sustain the apneic cycles. Blood gas level deviations are also increased.

By inserting longer aroused periods these apnea cycles can be made to persist as is shown in Figures 28-29.

Apnea density in the above case is similar to that reported in [48] for a four month old infant although the duration is longer (around 8 seconds as compared to five seconds)

8. Discussion. Much respiratory instability during sleep occurs during the transition to and during the phase of S1 sleep [59]. The above simulations have looked at the effects of changes in sleep transition time, shift in $S_{w}$ (the ventilatory drive set point) which simulates withdrawal of the awake stimulus, increases in the arousal threshold and levels for the minimum drive for obstruction. The shift in $S_{w}$ is assumed completed by the the time $\mathrm{S} 1$ is reached and in some cases we have considered that 


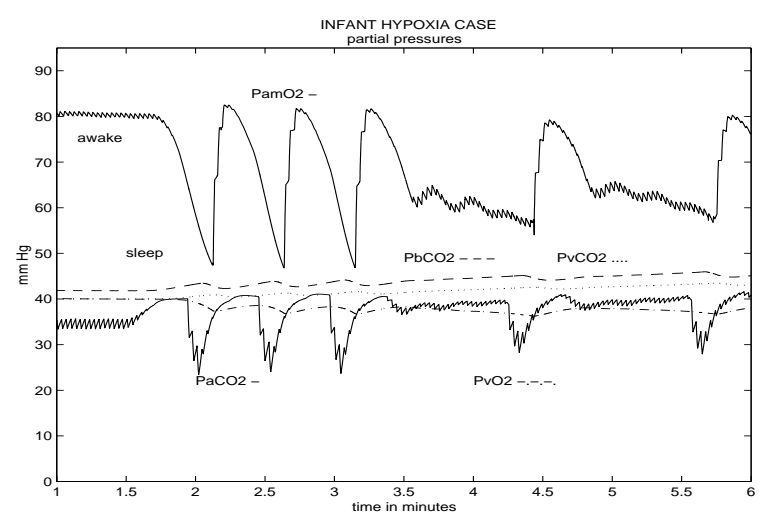

FIG. 25.

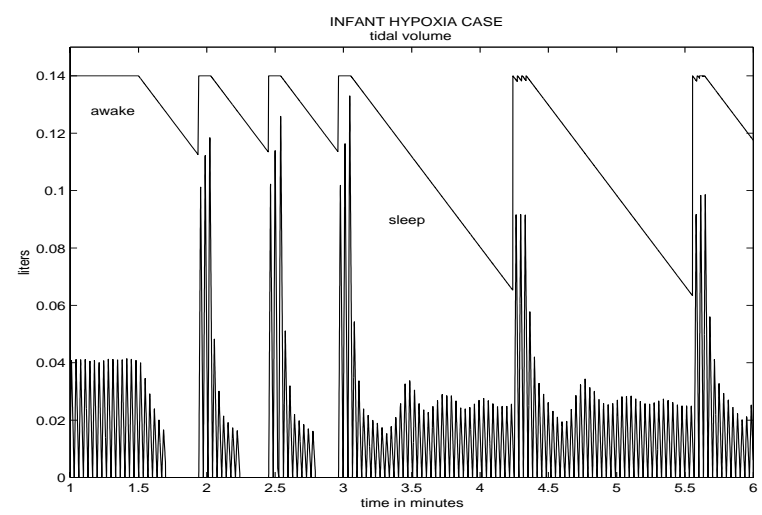

Fig. 26 .

this shift in $S_{w}$ is completed early in this transition phase. See Table 16. A variety of effects can be produced by various combinations of $S_{w}$ transition time, $S_{O}$ magnitude, arousal and minimum threshold levels and control gain levels. If the time for the $\mathbf{S}_{\mathrm{w}}$ shift is decreased then the magnitude of this shift can be reduced while producing the same level of disturbance. In the simulations producing instability we use as the transition time to $\mathrm{S} 1$ the value 20 seconds ([59]). We allow that the shift in $\mathrm{S}_{\mathrm{w}}$ can be completed before this transition is completed. A quick transition allows for smaller shift magnitudes which in turn produce steady state levels closer to normal levels. As the shift $S_{\mathrm{w}}$ is increased beyond the assumed normal value there are larger transient shifts in blood gas levels but they are still within a reasonable range of values as described in [9] for moderate shift maximums $S_{O}$. Larger maximal Shifts $S_{O}$ allow for a lower minimum drive point for obstruction and sustained cycles of apnea or a slower transition. These larger shifts would imply more extreme deviations in steady state values for the blood gases if permanent. However, large shifts which might be transitory would not produce such large deviations in steady state values. This might occur if strong transient effects on the ventilatory muscles occur during early sleep stages and then dissipate as time passes. Controller gain reduced $25 \%$ by stage 4 sleep produced steady state values consistent with observation [81]. Unlike the adult case, where Khoo [59] found that excessive reduction in the controller gain during 


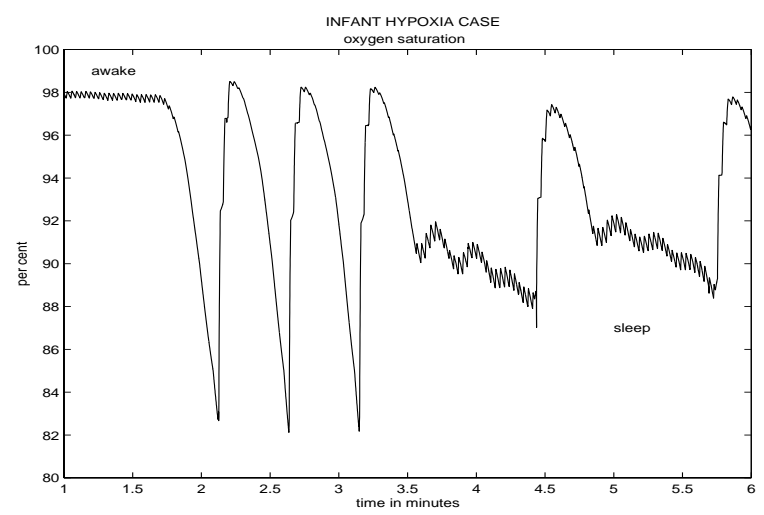

FIG. 27.

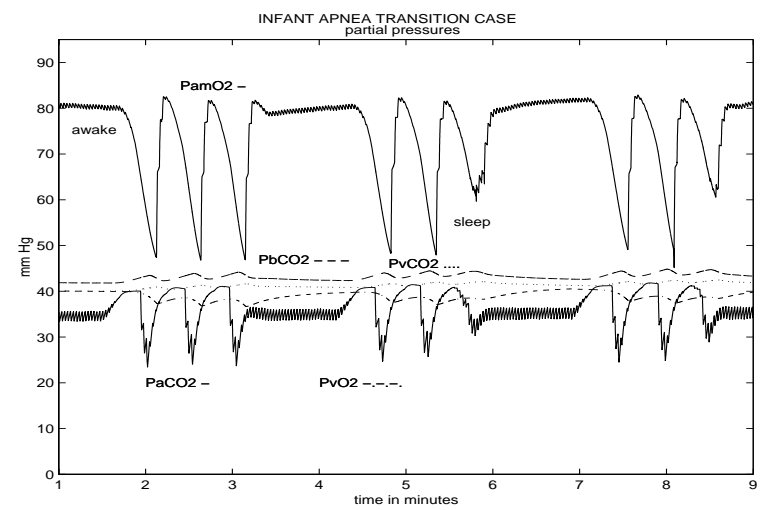

Fig. 28 .

sleep produces instability, it was not possible to similarly introduce such instabilities by controller gain alone in the infant case. With the nominal values fo $S_{O}, G_{C}$ and $G_{P}$ chosen to reflect the characteristics of blood gases in the infant sleep case, a combination of reduction in control gain and $S_{w}$ shift were required. It appears that the speed with which this shift occurs is of primary importance. In the infant case reducing controller gain could produce waking-sleeping cycles but even when controller gain was reduced to one fourth of normal by stage 4 sleep (with normal $S_{O}$ shift and short transition time) the transition to sleep did not produce apneic periods. Only an increased shift in $\mathrm{S}_{O}$ produced sufficient deviation to produce apnea. This is consistent with the results found in [22]. Based on the assumed values in the transition to sleep the minimum threshold for ventilatory drive is about one third the steady state ventilatory drive and the arousal threshold is twice the normal levels. The arousal thresholds can be increased resulting in longer apneic periods. The minimum drive needed for apneic episodes is higher than assumed in [59] (about twice the level) but for larger shifts in $S_{\mathrm{w}}$ and/or quicker transitions this level can be reduced. The parameter values were chosen as reasonable first guesses to these quantities. A parameter identification analysis would provide deeper insight into the key levels which contribute to apnea in infants. For example, a higher minimum threshold could indicate a feature of OA which occurs in cases where there is an elevated resistance to the dilating force of the 


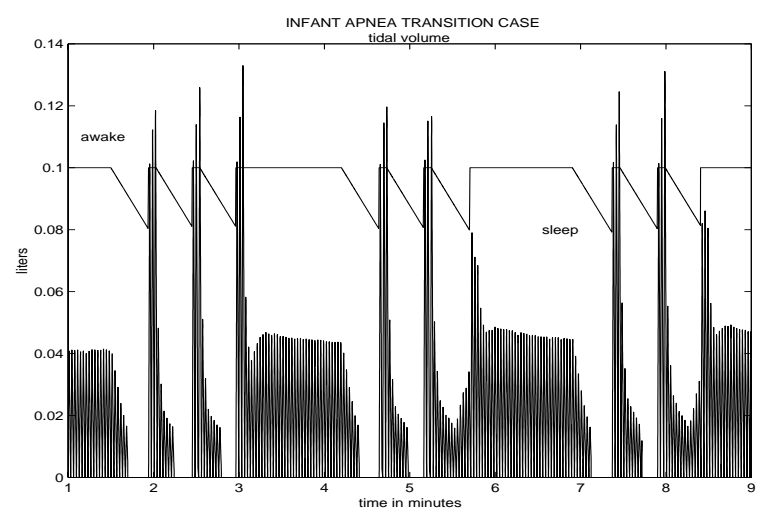

Fig. 29 .

ventilatory drive.

Respiratory instability is a potential risk factor for acute life threatening events and SIDS [30,39]. Such disturbances are caused by sleep/awake cycle disturbances, upper airway obstruction, temperature, sleep position and ventilatory controller functioning. Some infants at risk for SIDS may have deficiencies in the arousal mechanism $[17,42]$. Some researchers report higher incidence of OA but fewer arousals [17, 52] while other researchers have found no difference in the number of sleep/awake episodes for infants at risk for SIDS but observe abnormal patterns of the sleep/awake cycle [107]. Schectman et al. [107] report that while the mean arousal phenomena do not differ between control and at risk infants, there is greater difficulty in transiting to the awake state for infants at risk for SIDS. Studying the relation between the arousal threshold and other parameters might shed some light on the mechanisms implicated in SIDS.

It has been hypothesized that oscillatory patterns in blood gas levels are indicative of the stability of the respiratory control system with greater instability producing greater swings in these state variables [122]. Waggener et al have observed that while SIDS infants are not abnormal in the stability of the control system, one possible cause of SIDS may be that infants at risk have an abnormal susceptibility to prolonged apnea by obstruction or may be abnormaly suceptible to normal apneas [121]. This study has looked at the effects on respiratory stability of arousal thresholds, rightward shifts in ventilatory drive due to the withdrawal of the awake stimulus, increase in the minimal threshold for ventilation and loss of ventilatory drive during sleep. Higher arousal thresholds increase the apneic period and the reduction in $\mathrm{S}_{\mathrm{O}_{2}}$. Apneic oscillations can be damped out for certain combinations of the above factors and PB can be produced due to the cycling between the awake and sleep stages (generally S1). Table 16 summarizes these simulation results. The results of the simulations indicate a general stability to the infant breathing during transition to sleep except when the minimum threshold for obstruction as described above is assumed higher than might be expected or the transitional effects of sleep are assumed more severe. The interaction between the various forces affecting upper airway patency, the cycling between NREM and REM sleep and a complete description of the relation between central and obstructive apnea as well as the mechanisms terminating apnea remain to be described and may help provide a diagnostic scheme for recognizing infants at risk for SIDS. 


\section{APPENDIX}

TABLE 1

Physiological constants nominal values

\begin{tabular}{|c|c|c|c|c|}
\hline Quantity & Symbol & Unit & Value & Source \\
\hline \multirow[t]{3}{*}{ Metabolic rates } & $\mathrm{MR}_{\mathrm{B}_{\mathrm{CO}_{2}}}$ & $\mathrm{ml} / \mathrm{min} \mathrm{STPD}$ & 42 & {$[55]$} \\
\hline & $\mathrm{MR}_{\mathrm{T}_{\mathrm{CO}_{2}}}$ & $"$ & 220 & {$[55]$} \\
\hline & $\mathrm{MR}_{\mathrm{T}_{\mathrm{O}_{2}}}$ & $"$ & 270 & {$[55][56]$} \\
\hline \multirow[t]{6}{*}{ Partial pressures } & $\mathrm{PaCO}_{2}$ & $\mathrm{~mm} \mathrm{Hg}$ & 40 & {$[82]$} \\
\hline & $\mathrm{Pa}_{\mathrm{O}_{2}}$ & $"$ & 100 & {$[82]$} \\
\hline & $\mathrm{PV}_{\mathrm{CO}_{2}}$ & $"$ & 46 & {$[82]$} \\
\hline & $\mathrm{PV}_{\mathrm{O}_{2}}$ & $"$ & 40 & {$[82]$} \\
\hline & $\mathrm{P}_{\mathrm{BCO}_{2}}$ & $"$ & 49 & {$[36]$} \\
\hline & $\mathrm{P}_{\mathrm{BO}_{2}}$ & $"$ & 37 & {$[36]$} \\
\hline Tidal volume & V tidal & $\mathrm{ml} /$ breath & 450 & {$[80]$} \\
\hline Dead space volume & $\dot{\mathrm{V}}_{\mathrm{D}}$ & $\mathrm{ml}$ & 150 & {$[80]$} \\
\hline Alveolar flow rate & $\dot{\mathrm{V}}_{\mathrm{A}}$ & liters/min & 4 & {$[80]$} \\
\hline Minute volume & $\dot{\mathrm{V}}_{\mathrm{I}}$ & $"$ & $5-7$ & {$[80]$} \\
\hline Alveolar to capillary matching constant & $A-a$ & $\mathrm{~mm} \mathrm{Hg}$ & 4 & {$[80,85,88]$} \\
\hline \multirow[t]{5}{*}{ Volume of compartment } & $\mathrm{M}_{\mathrm{B}_{\mathrm{CO}_{2}}}$ & liter & .9 & {$[55]$} \\
\hline & $\mathrm{M}_{\mathrm{T}_{\mathrm{CO}_{2}}}$ & $"$ & 15 & {$[55]$} \\
\hline & $\mathrm{M}_{\mathrm{T}_{\mathrm{O}_{2}}}$ & $"$ & 6 & {$[55]$} \\
\hline & $\mathrm{M}_{\mathrm{LCO}_{2}}$ & $"$ & 3.2 & {$[55]$} \\
\hline & $\mathrm{M}_{\mathrm{L}_{\mathrm{O}_{2}}}$ & $"$ & 2.5 & {$[55]$} \\
\hline \multirow[t]{2}{*}{ Blood Flow Rates } & $\dot{\mathrm{Q}}$ & liters/min & 6 & {$[80]$} \\
\hline & $\dot{\mathrm{Q}}_{\mathrm{B}}$ & $"$ & 0.8 & {$[80]$} \\
\hline Shunt Factor & $\mathrm{EF}$ & $"$ & 0.9 & {$[80]$} \\
\hline
\end{tabular}

TABLE 2

Control constants nominal values

\begin{tabular}{lllll}
\hline Quantity & Symbol & Unit & Value & Source \\
\hline Central control gain & $\mathrm{G}_{\mathrm{C}}$ & $\mathrm{mm} \mathrm{Hg} / \mathrm{min}$ & $1.8\left(^{*} 2.5\right.$ for breath model $)$ & {$[59]$} \\
Peripheral control gain & $\mathrm{G}_{\mathrm{P}}$ & $"$ & $0.14\left({ }^{*} 2.5\right.$ for breath model $)$ & {$[59]$} \\
Central apneic threshold & $\mathrm{I}_{\mathrm{C}}$ & $\mathrm{mm} \mathrm{Hg}$ & 37.0 & {$[59]$} \\
Peripheral apneic threshold & $\mathrm{I}_{\mathrm{P}}$ & $\mathrm{mm} \mathrm{Hg}$ & 37.0 & {$[59]$} \\
\hline
\end{tabular}


TABLE 3

Transport delays nominal values

\begin{tabular}{lllll}
\hline & Symbol & Unit & Value & Source \\
\hline Quantity & $\tau_{\mathrm{B}}$ & $\mathrm{sec}$ & 12.0 (including mixing) & {$[36,60]$} \\
Lung to brain & & $\mathrm{sec}$ & 19.0 (including mixing) & {$[36,60,118]$} \\
Lung to carotid artery & $\tau_{\mathrm{a}}$ & $\mathrm{sec}$ & 10.0 (including mixing) & {$[36,60]$} \\
Tissue to lung & $\tau_{\mathrm{V}}$ & $\mathrm{sec}$ & 22.0 (including mixing) & {$[36,60,118]$} \\
Mixing and Distortion & $\tau_{1}$ & $\mathrm{sec}$ & 3 & {$[60]$} \\
\hline
\end{tabular}

TABLE 4

Arterial segment volume nominal values

\begin{tabular}{llll}
\hline & Unit & Value & Source \\
\hline Quantity & liter & 1.06 & {$[36]$} \\
Carotid to peripheral sensors & $"$ & 0.008 & {$[36]$} \\
Peripheral sensors to brain & $"$ & 0.008 & {$[36]$} \\
Lung to tissue compartment & $"$ & 1.735 & {$[36]$} \\
Tissue compartment to lung & $"$ & 3.12 & {$[36]$} \\
\hline
\end{tabular}

TABLE 5

Dissociation constants nominal values

\begin{tabular}{|c|c|c|c|c|}
\hline Quantity & Symbol & Unit & Value & Source \\
\hline $\mathrm{CO}_{2}$ constant & $\mathrm{K}_{\mathrm{CO}_{2}}$ & $\mathrm{~mm} \mathrm{Hg}^{-1}$ & .0057 & {$[59]$} \\
\hline $\mathrm{O}_{2}$ venous slope at $\mathrm{P}_{\mathrm{V}_{\mathrm{O}_{2}}}<55$ & $\mathrm{~m}_{\mathrm{V}}$ & $"$ & .0021 & {$[57]$} \\
\hline $\mathrm{O}_{2}$ venous constant at $\mathrm{P}_{\mathrm{V}_{2}}<55$ & $\mathrm{~B}_{\mathrm{v}}$ & $"$ & .0662 & {$[57]$} \\
\hline $\mathrm{O}_{2}$ venous slope at $55<\mathrm{P}_{\mathrm{V}_{\mathrm{O}}}<70$ & $\mathrm{~m}_{\mathrm{V}}$ & $"$ & .00067 & {$[57]$} \\
\hline $\mathrm{O}_{2}$ venous constant at $55<\mathrm{P}_{\mathrm{V}_{\mathrm{O}_{2}}}<70$ & $\mathrm{~B}_{\mathrm{V}}$ & $"$ & .1434 & {$[57]$} \\
\hline $\mathrm{O}_{2}$ venous slope at $70<\mathrm{P}_{\mathrm{V}_{2}}$ & $\mathrm{~m}_{\mathrm{V}}$ & $"$ & .00025 & {$[57]$} \\
\hline $\mathrm{O}_{2}$ venous constant at $70<\mathrm{P}_{\mathrm{O}_{2}}$ & $\mathrm{~B}_{\mathrm{V}}$ & $"$ & .1728 & {$[57]$} \\
\hline $\mathrm{O}_{2}$ arterial slope at $\mathrm{Pa}_{\mathrm{O}_{2}}<55$ & $\mathrm{~m}_{\mathrm{a}}$ & $"$ & .0021 & {$[57]$} \\
\hline $\mathrm{O}_{2}$ arterial constant at $\mathrm{P}_{\mathrm{O}_{2}}<55$ & $\mathrm{Ba}_{\mathrm{a}}$ & $"$ & .0662 & {$[57]$} \\
\hline $\mathrm{O}_{2}$ arterial slope at $55<\mathrm{Pa}_{\mathrm{O}_{2}}<70$ & $\mathrm{~m}_{\mathrm{a}}$ & $"$ & .00067 & {$[57]$} \\
\hline $\mathrm{O}_{2}$ arterial constant at $55<\stackrel{\mathrm{P}}{\mathrm{P}}_{\mathrm{O}_{2}}<70$ & $\mathrm{~B}_{\mathrm{a}}$ & $"$ & .1434 & {$[57]$} \\
\hline $\mathrm{O}_{2}$ arterial slope at $70<\mathrm{Pa}_{\mathrm{O}_{2}}$ & $\mathrm{~m}_{\mathrm{a}}$ & $"$ & .00025 & {$[57]$} \\
\hline $\mathrm{O}_{2}$ arterial constant at $70<\mathrm{P}_{\mathrm{O}_{2}}$ & $\mathrm{~B}_{\mathrm{a}}$ & $"$ & .1728 & {$[57]$} \\
\hline
\end{tabular}


TABLE 6

Physical constants nominal values

\begin{tabular}{|c|c|c|c|c|}
\hline Quantity & Symbol & Unit & Value & Source \\
\hline Ambient pressure & $\mathrm{P}_{\mathrm{AT}}$ & $\mathrm{mm} \mathrm{Hg}$ & 760 sea level & {$[80]$} \\
\hline Fraction of inspired $\mathrm{CO}_{2}$ & $\mathrm{~F}_{\mathrm{I}_{\mathrm{CO}_{2}}}$ & $\%$ & .04 & {$[80]$} \\
\hline Fraction of inspired $\mathrm{O}_{2}$ & $\mathrm{~F}_{\mathrm{I}_{\mathrm{O}_{2}}}$ & $\%$ & 20.94 & {$[80]$} \\
\hline Inspired pressure $\mathrm{CO}_{2}$ & $\mathrm{P}_{\mathrm{I}_{\mathrm{CO}_{2}}}$ & $\%$ & $\left(\mathrm{P}_{\mathrm{B}}-\mathrm{P}_{\mathrm{W}}\right) \mathrm{F}_{\mathrm{I}_{\mathrm{CO}_{2}}}$ & {$[80]$} \\
\hline Inspired pressure $\mathrm{O}_{2}$ & $\mathrm{P}_{\mathrm{I}_{\mathrm{O}_{2}}}$ & $\%$ & $\left(\mathrm{P}_{\mathrm{B}}-\mathrm{P}_{\mathrm{W}}\right) \mathrm{F}_{\mathrm{I}_{\mathrm{O}_{2}}}$ & {$[80]$} \\
\hline
\end{tabular}


TABLE 7

Parameter and I.C. values for congestive heart case

\begin{tabular}{|c|c|c|c|}
\hline Parameter & Value & Unit & Source \\
\hline Central control gain & $1.88^{*}$ & liter/min $/ \mathrm{mm} \mathrm{Hg}$ & {$[60]$} \\
\hline Peripheral control gain & $0.135 *$ & liter $/ \mathrm{min} / \mathrm{mm} \mathrm{Hg}$ & [60] \\
\hline Central apneic threshold & 39.0 & $\mathrm{~mm} \mathrm{Hg}$ & [59] \\
\hline Peripheral apneic threshold & 39.0 & $\mathrm{~mm} \mathrm{Hg}$ & [59] \\
\hline Cardiac output & 3.0 & liter $/ \mathrm{min}$ & {$[60]$} \\
\hline Lung to tissue delay & 35.0 estimated & $\sec$ & [60] \\
\hline Tissue to lung delay & 41.0 estimated & $\sec$ & {$[60]$} \\
\hline Lung to brain delay & 21.0 & $\sec$ & [60] \\
\hline Lung to carotid delay & 17.0 & $\sec$ & {$[60]$} \\
\hline $\mathrm{PaCO} 2$ & 42.0 & $\mathrm{~mm} \mathrm{Hg}$ & [60] \\
\hline $\mathrm{PaO} 2$ & 85.0 & $\mathrm{~mm} \mathrm{Hg}$ & [60] \\
\hline PVCO2 & 49.0 estimated & $\mathrm{mm} \mathrm{Hg}$ & [60] \\
\hline PVO2 & 25.0 estimated & $\mathrm{mm} \mathrm{Hg}$ & [60] \\
\hline $\mathrm{PBCO} 2$ & 50.0 estimated & $\mathrm{mm} \mathrm{Hg}$ & {$[60]$} \\
\hline
\end{tabular}


TABLE 8

Parameter values for adult simulations

\begin{tabular}{|c|c|c|c|}
\hline Simulation & Quantity & Value & Source \\
\hline \multirow[t]{11}{*}{ Figures $11-12$} & $\mathrm{G}_{\mathrm{P}}$ & $0.14^{*}$ & {$[59]$} \\
\hline & $\mathrm{G}_{\mathrm{C}}$ & $1.8 *$ & {$[59]$} \\
\hline & $\dot{\mathrm{Q}}$ & $6.001 / \mathrm{min}$ & {$[55]$} \\
\hline & $\dot{\mathrm{Q}}_{\mathrm{B}}$ & $0.751 / \mathrm{min}$ & estimate [28] \\
\hline & $\mathrm{G}_{\mathrm{W}} \min$ & 0.6 & {$[59]$} \\
\hline & $\mathrm{S}_{\mathrm{O}}$ & $5.4 * 1 / \mathrm{mi} 180$ & {$[59]$} \\
\hline & S4 sleep transition & $180 \mathrm{sec}$ & {$[59]$} \\
\hline & min drive for obstruction & $1.2 * 1 / \mathrm{min}$ & {$[59]$} \\
\hline & arousal threshold & $18.6 * 1 / \mathrm{min}$ & {$[59]$} \\
\hline & obstruction removal threshold & $18.6 * 1 / \mathrm{min}$ & {$[59]$} \\
\hline & expire and tidal multiplier for $\dot{\mathrm{V}}_{\mathrm{I}}$ & 0.1 & \\
\hline \multirow[t]{11}{*}{ Figures $13-15$} & $\mathrm{G}_{\mathrm{P}}$ & $0.11^{\star}$ & {$[59]$} \\
\hline & $\mathrm{G}_{\mathrm{C}}$ & $1.8 *$ & {$[59]$} \\
\hline & $\dot{\mathrm{Q}}$ & $6.001 / \mathrm{min}$ & {$[55]$} \\
\hline & $\dot{\mathrm{Q}}_{\mathrm{B}}$ & $0.75 \mathrm{l} / \mathrm{min}$ & estimate [28] \\
\hline & $\mathrm{G}_{\mathrm{W}} \mathrm{min}$ & 0.25 & estimate $[55]$ \\
\hline & $\mathrm{S}_{\mathrm{O}}$ & $6.6 * 1 / \mathrm{min}$ & {$[59]$} \\
\hline & S4 sleep transition & $80 \mathrm{sec}$ & {$[59]$} \\
\hline & min drive for obstruction & $1.6 * 1 / \mathrm{min}$ & {$[59]$} \\
\hline & arousal threshold & $18.6 * 1 / \mathrm{min}$ & {$[59]$} \\
\hline & obstruction removal threshold & $18.6 * 1 / \mathrm{min}$ & {$[59]$} \\
\hline & expire and tidal multiplier for $\dot{\mathrm{V}}_{\mathrm{I}}$ & 0.1 & \\
\hline
\end{tabular}

* multiply by 2.5 for breath model 
TABLE 9

Nominal parameter values for awake new born infant at $3.2 \mathrm{~kg}$

\begin{tabular}{|c|c|c|c|}
\hline Parameter & Value & Unit & Source \\
\hline Central control gain & $0.10^{*}$ & liter/min/mm Hg & {$[102,87]$} \\
\hline Central apneic threshold & 29.0 & $\mathrm{~mm} \mathrm{Hg}$ & {$[87]$} \\
\hline Peripheral control gain & $2.0 *$ & liter $/ \mathrm{min} / \mathrm{mm} \mathrm{Hg}$ & {$[87]$} \\
\hline Peripheral apneic threshold & 29.0 & $\mathrm{~mm} \mathrm{Hg}$ & {$[87]$} \\
\hline $\mathrm{CO}_{2}$ effective lung volume & 0.11 & liters & {$[87,100]$} \\
\hline $\mathrm{O}_{2}$ effective lung volume & 0.092 & liters & {$[87,100]$} \\
\hline ventilatory dead space & 0.009 & liters & [85] \\
\hline $\mathrm{CO}_{2}$ effective tissue volume & 1.05 & liters & [100] \\
\hline $\mathrm{O}_{2}$ effective tissue volume & 0.24 & liters & {$[100]$} \\
\hline $\mathrm{CO}_{2}$ effective brain volume & 0.10 & liters & {$[87,59]$ estimate } \\
\hline $\mathrm{CO}_{2}$ tissue metabolic rate & .018 & liters/minute & {$[100,85,87]$} \\
\hline $\mathrm{O}_{2}$ tissue metabolic rate & 0.02 & liters/minute & {$[100,85,87]$} \\
\hline respiration quotient $R Q$ & 0.90 & $\mathrm{CO}_{2} / \mathrm{O}_{2}$ ratio & {$[100,85]$} \\
\hline $\mathrm{CO}_{2}$ brain metabolic rate & 0.004 & liters/minute & [113] estimate \\
\hline breath frequency & 30 & breaths / $\mathrm{min}$ & {$[45,29]$} \\
\hline inspiratory time & 0.8 & $\sec$ & [85] \\
\hline expiratory time & 1.2 & $\sec$ & [85] \\
\hline alveolar/capillary $\mathrm{O}_{2}$ difference & $20-30$ & $\mathrm{~mm} \mathrm{Hg}$ & {$[113,85]$} \\
\hline Cardiac output & 0.68 & liter $/ \mathrm{min}$ & {$[113,100]$} \\
\hline Cerebral blood flow & 0.14 & liter $/ \mathrm{min}$ & [113] \\
\hline $\mathrm{R} / \mathrm{L}$ cardiac shunt factor & 0.10 & & {$[113,100,88,85]$} \\
\hline
\end{tabular}


TABLE 10

Parameter value changes for awake 4 month old infant at $6 \mathrm{~kg}$

\begin{tabular}{|c|c|c|c|}
\hline Parameter & Value & Unit & Source \\
\hline Central control gain & $0.10^{*}$ & liter $/ \mathrm{min} / \mathrm{mm} \mathrm{Hg}$ & {$[102,87]$} \\
\hline Central apneic threshold & 26.0 & $\mathrm{~mm} \mathrm{Hg}$ & {$[100]$} \\
\hline Peripheral control gain & $2.0 *$ & liter/min/mm Hg & {$[87]$} \\
\hline Peripheral apneic threshold & 26.0 & $\mathrm{~mm} \mathrm{Hg}$ & {$[100]$} \\
\hline $\mathrm{CO}_{2}$ tissue metabolic rate & .032 & liters/minute & {$[100,85,87]$} \\
\hline respiration quotient $R Q$ & 0.85 & $\mathrm{CO}_{2} / \mathrm{O}_{2}$ ratio & {$[100,85]$} \\
\hline breath frequency & 30 & breaths / min & {$[45,29]$} \\
\hline inspiratory time & 0.8 & $\sec$ & {$[85]$} \\
\hline expiratory time & 1.2 & $\sec$ & {$[85]$} \\
\hline alveolar/capillary $\mathrm{O}_{2}$ difference & 13 & $\mathrm{~mm} \mathrm{Hg}$ & {$[113,100,85]$} \\
\hline Cardiac output & 1.16 & liter $/ \mathrm{min}$ & {$[100]$} \\
\hline Cerebral blood flow & 0.24 & liter/min & {$[100]$} \\
\hline $\mathrm{R} / \mathrm{L}$ cardiac shunt factor & 0.055 & & \\
\hline
\end{tabular}

* multiply by 2.5 for breath model

scale other parameters by weight 
TABLE 11

Nominal delay parameter values for infant simulations

\begin{tabular}{|c|c|c|c|}
\hline Parameter & Value & Unit & Source \\
\hline Lung to tissue delay & 8.0 estimated & $\sec$ & {$[87][100]$} \\
\hline tissue to lung delay & 9.0 estimated & $\sec$ & {$[87][100]$} \\
\hline Lung to brain delay & 4.0 & $\sec$ & {$[87][100]$} \\
\hline Lung to carotid delay & 3 & $\sec$ & {$[87][100]$} \\
\hline mixing delay & 2 & $\sec$ & {$[87][100]$} \\
\hline $\mathrm{P}_{\mathrm{V}_{\mathrm{O}_{2}}}$ delay to $\mathrm{Pam}_{\mathrm{O}_{2}}$ mixing & $0.7^{*} \tau_{\mathrm{V}}$ delay $+0.7^{*} \tau_{\mathrm{T}}$ & $\sec$ & estimated \\
\hline \multicolumn{4}{|l|}{ for tissue compartment } \\
\hline $\mathrm{P}_{\mathrm{V}_{2}}$ delay to $\mathrm{Pam}_{\mathrm{O}_{2}}$ mixing for carotid sensor & $0.7^{*} \tau_{\mathrm{V}}+.4^{*} \tau_{\mathrm{a}}$ & sec & estimated \\
\hline for carotid sensor & & & \\
\hline
\end{tabular}

TABLE 12

Nominal Initial conditions for awake infant after 3-4 months

\begin{tabular}{lcll}
\hline State variable & Value & Unit & Source \\
\hline PaCO2 & 34.0 & mm Hg & {$[106,50,85]$} \\
PaO2 & 96.0 & $\mathrm{~mm} \mathrm{Hg}$ & {$[85]$} \\
PamO2 & 79.0 & $\mathrm{~mm} \mathrm{Hg}$ & {$[85,81,50,106]$} \\
PVCO2 & 40.0 & mm Hg & {$[85]$ estimate } \\
PVO2 & 40.0 & mm Hg & {$[85]$ estimate } \\
PBCO2 & 43.0 & mm Hg & {$[85]$ estimate } \\
breath frequency & 30 & breaths $/ \mathrm{min}$ & {$[85,29]$} \\
V & & liters $/ \mathrm{breath}$ & {$[110,29,73,85]$} \\
V & .04 & liters $/ \mathrm{min}$ & {$[110,29,85]$} \\
\hline
\end{tabular}


TABLE 13

Dissociation constants nominal values for 3-4 month infant

\begin{tabular}{|c|c|c|c|c|}
\hline Quantity & Symbol & Unit & Value & Source \\
\hline $\mathrm{CO}_{2}$ constant & $\mathrm{K}_{\mathrm{CO}_{2}}$ & $\mathrm{~mm} \mathrm{Hg}^{-1}$ & .0050 & {$[100][20]$} \\
\hline $\mathrm{O}_{2}$ venous slope at $\mathrm{P}_{\mathrm{V}_{\mathrm{O}_{2}}}<35$ & $m_{\mathrm{v}}$ & $"$ & .00307 & {$[100],[20]$} \\
\hline $\mathrm{O}_{2}$ venous constant at $\mathrm{P}_{\mathrm{V}_{\mathrm{O}_{2}}}<35$ & $\mathrm{~B}_{\mathrm{v}}$ & $"$ & -.0122 & {$[100],[20]$} \\
\hline $\mathrm{O}_{2}$ venous slope at $35<\mathrm{P}_{\mathrm{V}_{2}}<45$ & $m_{v}$ & " & .00199 & {$[100],[20]$} \\
\hline $\mathrm{O}_{2}$ venous constant at $35<\mathrm{P}_{\mathrm{V}_{\mathrm{O}_{2}}}<45$ & $\mathrm{~B}_{\mathrm{v}}$ & " & .0255 & {$[100],[20]$} \\
\hline $\mathrm{O}_{2}$ venous slope at $45<\mathrm{P}_{\mathrm{V}_{\mathrm{O}_{2}}}<55$ & $m_{v}$ & $"$ & .00116 & {$[100],[20]$} \\
\hline $\mathrm{O}_{2}$ venous constant at $45<\mathrm{P}_{\mathrm{V}_{\mathrm{O}_{2}}}<55$ & $\mathrm{~B}_{\mathrm{v}}$ & $"$ & .0625 & {$[100],[20]$} \\
\hline $\mathrm{O}_{2}$ venous slope at $55<\mathrm{P}_{\mathrm{V}_{\mathrm{O}_{2}}}<70$ & $m_{v}$ & ” & .00057 & {$[100],[20]$} \\
\hline $\mathrm{O}_{2}$ venous constant at $55<\mathrm{P}_{\mathrm{V}_{\mathrm{O}_{2}}}<70$ & $\mathrm{~B}_{\mathrm{v}}$ & " & .0953 & {$[100],[20]$} \\
\hline $\mathrm{O}_{2}$ venous slope at $70<\mathrm{P}_{\mathrm{V}_{2}}$ & $m_{v}$ & " & .000159 & {$[100],[20]$} \\
\hline $\mathrm{O}_{2}$ venous constant at $70<\mathrm{P}_{\mathrm{V}_{\mathrm{O}_{2}}}$ & $\mathrm{~B}_{\mathrm{v}}$ & " & .1242 & {$[100],[20]$} \\
\hline $\mathrm{O}_{2}$ arterial slope at $\mathrm{P}_{\mathrm{a}_{0}}<35$ & $m_{v}$ & " & .00307 & {$[100],[20]$} \\
\hline $\mathrm{O}_{2}$ arterial constant at $\mathrm{P}_{\mathrm{a}_{\mathrm{O}_{2}}}<35$ & $\mathrm{~B}_{v}$ & ” & -.0122 & {$[100],[20]$} \\
\hline $\mathrm{O}_{2}$ arterial slope at $35<\mathrm{P}_{\mathrm{O}_{2}}<45$ & $\mathrm{~m}_{\mathrm{a}}$ & " & .00199 & {$[100],[20]$} \\
\hline $\mathrm{O}_{2}$ arterial constant at $35<\mathrm{P}_{\mathrm{O}_{2}}<45$ & $\mathrm{~B}_{\mathrm{a}}$ & " & .0255 & {$[100],[20]$} \\
\hline $\mathrm{O}_{2}$ arterial slope at $45<\mathrm{Pa}_{\mathrm{O}_{2}}<55$ & $\mathrm{~m}_{\mathrm{a}}$ & " & .00116 & {$[100],[20]$} \\
\hline $\mathrm{O}_{2}$ arterial constant at $45<\mathrm{P}_{\mathrm{O}_{2}}<55$ & $\mathrm{~B}_{\mathrm{a}}$ & $"$ & .0625 & {$[100],[20]$} \\
\hline $\mathrm{O}_{2}$ arterial slope at $55<\mathrm{Pa}_{\mathrm{O}_{2}}<70$ & $\mathrm{~m}_{\mathrm{a}}$ & ” & .00057 & {$[100],[20]$} \\
\hline $\mathrm{O}_{2}$ arterial constant at $55<\mathrm{P}_{\mathrm{O}_{2}}<70$ & $\mathrm{~B}_{\mathrm{a}}$ & " & .0953 & {$[100],[20]$} \\
\hline $\mathrm{O}_{2}$ arterial slope at $70<\mathrm{Pa}_{\mathrm{O}_{2}}$ & $\mathrm{~m}_{\mathrm{a}}$ & ” & .000159 & {$[100],[20]$} \\
\hline $\mathrm{O}_{2}$ arterial constant at $70<\mathrm{P}_{\mathrm{a}_{2}}$ & $\mathrm{~B}_{\mathrm{a}}$ & $"$ & .1242 & {$[100],[20]$} \\
\hline
\end{tabular}


TABLE 14

$\mathrm{O}_{2}$ saturation constants

\begin{tabular}{|c|c|c|c|c|}
\hline Quantity & Symbol & Unit & Value & Source \\
\hline $\mathrm{S}_{\mathrm{O}_{2}}$ slope at $\mathrm{Pa}_{\mathrm{O}_{2}}<30$ & $\mathrm{~m}_{\mathrm{S}}$ & $"$ & 2.40 & {$[20]$} \\
\hline $\mathrm{S}_{\mathrm{O}_{2}}$ constant at $\mathrm{Pa}_{\mathrm{O}_{2}}<30$ & $\mathrm{~b}_{\mathrm{s}}$ & $"$ & 14.0 & {$[20]$} \\
\hline $\mathrm{S}_{\mathrm{O}_{2}}$ slope at $30<\mathrm{Pa}_{\mathrm{O}_{2}}<40$ & $\mathrm{~m}_{\mathrm{S}}$ & $"$ & 1.8 & {$[20]$} \\
\hline $\mathrm{S}_{\mathrm{O}_{2}}$ constant at $30<\mathrm{Pa}_{\mathrm{O}_{2}}<40$ & $\mathrm{~b}_{\mathrm{s}}$ & $"$ & 4.0 & {$[20]$} \\
\hline $\mathrm{S}_{\mathrm{O}_{2}}$ slope at $40<\mathrm{Pa}_{\mathrm{O}_{2}}<50$ & $\mathrm{~m}_{\mathrm{S}}$ & $"$ & .9 & {$[20]$} \\
\hline $\mathrm{S}_{\mathrm{O}_{2}}$ constant at $40<\mathrm{P}_{\mathrm{P}_{\mathrm{O}_{2}}}<50$ & $\mathrm{~b}_{\mathrm{s}}$ & $"$ & 40.0 & {$[20]$} \\
\hline $\mathrm{S}_{\mathrm{O}_{2}}$ slope at $50<\mathrm{Pa}_{\mathrm{O}_{2}}<60$ & $\mathrm{~m}_{\mathrm{S}}$ & $"$ & .5 & {$[20]$} \\
\hline $\mathrm{S}_{\mathrm{O}_{2}}$ constant at $50<\mathrm{Pa}_{\mathrm{O}_{2}}<60$ & $\mathrm{~b}_{\mathrm{s}}$ & $"$ & 60.0 & {$[20]$} \\
\hline $\mathrm{S}_{\mathrm{O}_{2}}$ slope at $60<\mathrm{Pa}_{\mathrm{O}_{2}}<70$ & $\mathrm{~m}_{\mathrm{S}}$ & $"$ & .4 & {$[20]$} \\
\hline $\mathrm{S}_{\mathrm{O}_{2}}$ constant at $60<\mathrm{Pa}_{\mathrm{O}_{2}}<70$ & $\mathrm{~b}_{\mathrm{S}}$ & $"$ & 66.0 & {$[20]$} \\
\hline $\mathrm{S}_{\mathrm{O}_{2}}$ slope at $70<\mathrm{Pa}_{\mathrm{O}_{2}}<80$ & $\mathrm{~m}_{\mathrm{S}}$ & $"$ & .37 & {$[20]$} \\
\hline $\mathrm{S}_{\mathrm{O}_{2}}$ constant at $70<\mathrm{Pa}_{\mathrm{O}_{2}}<80$ & $\mathrm{~b}_{\mathrm{s}}$ & $"$ & 68.1 & {$[20]$} \\
\hline $\mathrm{S}_{\mathrm{O}_{2}}$ slope at $80<\mathrm{Pa}_{\mathrm{O}_{2}}<85$ & $\mathrm{~m}_{\mathrm{S}}$ & $"$ & 0.32 & {$[20]$} \\
\hline $\mathrm{S}_{\mathrm{O}_{2}}$ constant at $80<\mathrm{Pa}_{\mathrm{O}_{2}}<85$ & $\mathrm{~b}_{\mathrm{s}}$ & $"$ & 72.1 & {$[20]$} \\
\hline $\mathrm{S}_{\mathrm{O}_{2}}$ slope at $85<\mathrm{Pa}_{\mathrm{O}_{2}}<88$ & $\mathrm{~m}_{\mathrm{S}}$ & $"$ & 0.2 & {$[20]$} \\
\hline $\mathrm{S}_{\mathrm{O}_{2}}$ constant at $85<\mathrm{Pa}_{\mathrm{O}_{2}}<88$ & $\mathrm{~b}_{\mathrm{s}}$ & $"$ & 82.2 & {$[20]$} \\
\hline $\mathrm{S}_{\mathrm{O}_{2}}$ slope at $88<\mathrm{Pa}_{\mathrm{O}_{2}}$ & $\mathrm{~m}_{\mathrm{S}}$ & $"$ & 0.10 & {$[20]$} \\
\hline $\mathrm{S}_{\mathrm{O}_{2}}$ constant at $88<\mathrm{Pa}_{\mathrm{O}_{2}}$ & $\mathrm{~b}_{\mathrm{s}}$ & $"$ & 91.8 & {$[20]$} \\
\hline
\end{tabular}

TABLE 15

Nominal sleep constants for 4 month old infants

\begin{tabular}{|c|c|c|c|}
\hline State variable & Value & Unit & Source \\
\hline $\mathrm{S}_{\mathrm{O}}$ & $0.4^{*}$ & $1 / \mathrm{min}$ & scaled from $[59]$ \\
\hline$G_{W} \min$ value & 0.85 & & {$[59,22]$} \\
\hline$\dot{\mathrm{Q}}$ reduction & $5 \%$ & & {$[59]$} \\
\hline $\mathrm{MR}_{\mathrm{T}_{\mathrm{CO}_{2}}}, \mathrm{MR}_{\mathrm{T}_{\mathrm{O}_{2}}}$ reduction & $12.00 \%$ & & scaled from [59] \\
\hline $\mathrm{MR}_{\mathrm{B}_{\mathrm{CO}_{2}}}$ reduction & $4.0 \%$ & & {$[59]$} \\
\hline arousal threshold & $2.4^{*}$ & $1 / \min$ & scaled from [59] \\
\hline removal of obstruction threshold & $2.4^{*}$ & $1 / \mathrm{min}$ & scaled from $[59]$ \\
\hline minimum drive for obstruction & $0.3 *$ & $1 / \min$ & scaled from $[59]$ \\
\hline $\mathrm{PaO} 2$ & 79.0 & $\mathrm{~mm} \mathrm{Hg}$ & {$[81,50]$} \\
\hline
\end{tabular}

multiply by 2.5 for breathmodel

$V_{I}=1.2 \mathrm{l} / \mathrm{min}$ (multiply by 2.5 for breathmodel) 
TABLE 16

Stability results for infant sleep cases

\begin{tabular}{|c|c|c|c|c|c|c|}
\hline type & $\begin{array}{l}\min \\
\dot{\mathrm{V}}_{\mathrm{S}}\end{array}$ & $\begin{array}{l}\mathrm{S} 4 \mathrm{G}_{w} \\
\text { reduction }\end{array}$ & $\begin{array}{c}\text { arousal } \\
\text { threshold * }\end{array}$ & $\begin{array}{c}\mathrm{S}_{\mathrm{O}} \\
\text { shift }\end{array}$ & $\begin{array}{c}\mathrm{S}_{\mathrm{O}} \\
\text { shift time } * *\end{array}$ & $\begin{array}{c}\max \mathrm{S}_{\mathrm{O}_{2}} \\
\mathrm{drop}\end{array}$ \\
\hline stable transition & 0.3 & $15 \%$ & 2.4 & 0.40 & $30 \mathrm{sec}$ & $2 \%$ \\
\hline disturbed sleep cycle & 0.46 & $40 \%$ & 2.2 & 0.9 & $12 \mathrm{sec}$ & $8 \%$ \\
\hline apnea/arousal cycle & 0.46 & $60 \%$ & 2.6 & 1.12 & $16 \mathrm{sec}$. & $15.0 \%$ \\
\hline hypoxia/apnea cycle & 0.46 & $60 \%$ & 2.9 & 1.12 & $16 \mathrm{sec}$. & $18.0 \%$ \\
\hline hypoxic/apnea cycle & 0.46 & $60 \%$ & 3.0 & 1.40 & $20 \mathrm{sec}$ & $18.5 \%$ \\
\hline severe hypoxia cycle & 0.46 & $60 \%$ & 3.0 & 0.82 & $10 \mathrm{sec}$ & $18.5 \%$ \\
\hline $\begin{array}{l}{ }^{*} \text { multiply by } 2.5 \\
\text { for breath model }\end{array}$ & \#* transition & to S1 & is & $20 \mathrm{sec}$. & except & case 1 \\
\hline
\end{tabular}




\section{REFERENCES}

[1] Avery,G. Neonatology. J.B. Lippincott, Philadelphia,Pa., 1975.

[2] Badr, M.S. Effect of ventilatory drive on upper airway patency in humans during NREM sleep. Resp.Physiol., 103:1-10, 1996.

[3] Beckerman, R.C., Brouillette, R.T., and Hunt,C.E. Respiratory Control Disorders in Infants and Children. Williams and Wilkins, Baltimore, Md., 1992.

[4] Berger, A., Mitchell, R., and Severinghaus, J. Regulation of respiration. New England Journal of Medicine, 297(4):194-201, 1977.

[5] Berne, R. and Levy, M. Principles of Physiology 2nd edition. C.V. Mosby, St.Louis, 1995.

[6] Bradley, T.D., McNicholas, W.T., Rutherford,R., Popkin,J., Zamel,N., and Phillipson,E.A. Clinical and physiologic heterogeneity of the central sleep apnea syndrome. Am.Rev.Resp.Dis., 134:217-221, 1986.

[7] Bradley, T.D. and Phillipson, E.A. Pathogenesis and pathophysiology of the O.S.A. syndrome. Med.Clin.North.Amer., 69(6):1169-1185, 1985.

[8] Brady, J.P. and Mcann, E.M. Control of ventilation in subsequent siblings of victims of SIDS. Journal of Pediatrics, 106(2):212-217, 1985.

[9] Brouillette, R.T. Assessing cardiopulmonary function during sleep in infants and children. In R.G. Beckerman, R.T. Brouillette, and C.E. Hunt, editors, Respiratory Control Disorders in Infants and Children, pages 125-141. Williams and Wilkins-Baltimore Md., 1992.

[10] Bryan, A.C, Bowes, G., and Maloney, J.E. Control of breathing in the fetus and newborn. In Fishman A.P., editor, Handbook of Physiology, The Respiratory System, Part II, pages 621-647. American Physiol. Soc. Bethesda Md., 1986.

[11] Burgess, W.R. and Chemick, V. Respiratory Therapy in Newborn Infants and Children. Thieme, New York, 1986.

[12] Carley, D.W. and Shannon, D.C. A minimal mathematical model of human periodic breathing. J. Appl. Physiol., 65(3):1400-1409, 1988.

[13] Carley, D.W. and Shannon, D.C. Relative stability of respiration during progessive hypoxia. J.Appl.Physiol, 65(3):1389-1399, 1988.

[14] Carlo,W.A. and DiFiore,J.M. Respiratory muscle responses to changes in chemoreceptor drive in infants. J.Appl.Physiol., 68(3):1041-1047, 1990.

[15] Cherniack, N.S. Respiratory dysrythmias during sleep. New Eng. J. Med., 305(6):325-330, 1981.

[16] Cooke, K. and Grossman, Z. Discrete delay,distributed delay and stability switches. J.Math.Analys.Appl., 86:592-627, 1982.

[17] Coons, S. and Guilleminault, C. Motility and arousal in near miss SIDS. J. Pediatr., $107(5): 728-732,1985$.

[18] Crystal, R.G. and West,J.B. et al. The Lung: Scientific foundations 2nd edition. Raven Press, N.Y. N.Y., 1997.

[19] Cunningham, D.C, Robbins, P.A., and Wolff, C.B. Integration of respiratory responses. In Fishman A.P., editor, Handbook of Physiology, The Respiratory System, Part II, pages 475-528. American Physiol. Soc. Bethesda Md., 1986.

[20] Delivoria-Papadopoulos,M, and DiGiacomo, J.E. Oxygen transport and delivery. In R.A. Polin and W.W. Fox, editors, Fetal and Neonatal Physiology Volume 1, pages 801-813. W.B. Saunders, Philadelphia, 1992.

[21] Dempsey, J.A., Harms,C., Morgan,B., Badr,M.S., and Skatrud,J.B. Sleep effects on breathing and breathing stability. In R.G. Crystal, J.B. West, P.J. Barnes, N.S. Cherniack, and E.R. Weibel, editors, The Lung: Scientific Foundations, pages 2063-2071. Lippincott-Raven N.Y., 1997.

[22] Dempsey,J.A. and Skatrud,J.B. A sleep-induced apneic threshold and its consequences. Am.Rev.Resp.Dis., 133(6):1163-1170, 1986.

[23] Douglas, C.G. and Haldane, J.S. Causes of PB or CSR. J. Physiol. Lond., 38:401-419, 1909.

[24] Dyson, M., Beckerman,R.C., and Brouillette,R.T. Obstructive sleep apnea syndrome. In R.G. Beckerman, R.T. Brouillette, and C.E. Hunt, editors, Respiratory Control Disorders in Infants and Children, pages 212-230. Williams and Wilkins-Baltimore Md., 1992.

[25] Elhefnawy, A., Saidel, G.M., and Bruce, E.N. $\mathrm{CO}_{2}$ control of the respiratory system: plant dynamics and stability analysis. Annals of Biomed. Eng., 16:445-461, 1988.

[26] Engelberts,A.C. The role of obstructive apnea in SIDS and ALTE. Int.J.Ped.Oto.Rhynolaryng., 32(Suppl.):S59-S62, 1995.

[27] Fenner, A., Schalk, V., Hoenicke, H., Wendenburg, A., and Roehling, T. Periodic breathing in premature and neonatal babies: breathing patterns, respiatory gas tensions, response to 
the changes in ambient air. Pediatr. Res., 7(4):174-183, 1973.

[28] Fincham, W.F. and Tehrani, F.T. On the regulation of cardiac output and cerebral blood flow. J. Biomed. Eng., 5:73-75, 1983.

[29] Gaultier, C. Overview of infant respiratory physiology during sleep. Bull.Europ.Physiol.Resp., 21(1):55-112, 1985.

[30] Gaultier, C. Cardio-respiratory adaptation during sleep in infants and children. Ped. Pulmon., 19:105-117, 1995.

[31] Gaultier,C. Obstructive sleep apnea syndrome in infants and children:established facts and unsettled issues. Thorax, 50:1204-1210, 1995.

[32] Gothe, B., van Lunteren, E., and Dick, T.E. Influence of the sleep state on respiratory muscle function. In N.A. Saunders and C.E. Sullivan, editors, Sleep and Breathing, pages 239-256. Marcel Dekker, N.Y., 1994.

[33] Gray, J.S. Multiple factory theory of the control of respiratory ventilation. Science, 102:739$744,1946$.

[34] Greenough, A. and Milner,A.D. Control of the respiratory system. In A. Greenough, N.R. Roberton, and A. Milner, editors, Neonatal Respiratory Disorders, pages 27-47. Arnold, London, 1996.

[35] Grodins, F.S. Models of respiration. In T.F. Hornbein, editor, Regulation of Breathing: Part II, pages 1313-1351. Marcel Dekker N.Y., 1981.

[36] Grodins, F.S., Buell, J., and Bart, A.J. Mathematical analysis and digital simulation of the respiratory control system. J. Appl. Physiology, 22(2):260-276, 1967.

[37] Grodins, F.S., Gray, J.S., Schroeder, K.R., Norins, A.I., and Jones, R.W. Respiratory responses to $\mathrm{CO}_{2}$ inhalation: A theoretical study of a nonlinear biological regulator. $J$. Appl. Physiol., 7:283-308, 1954.

[38] Guilleminault, C . Sleep-related respiratory function and dysfunction in post-neonatalinfantile apnea. In J.L. Culbertson, H.F. Krous, and R.D. Bendell, editors, Sudden Infant Death Syndrome, Medical Aspects and Psychological Management, pages 94-120. John Hopkins Univ.Press. Baltimore, 1988.

[39] Guilleminault, C., Stoohs,R., Skrobal,A., Labonowski,M., and Simmons,J. Upper airway resistance in infants at risk for SIDS. J. Pediatr., 122(6):881-886, 1993.

[40] Guyton, A.C. Physiology of the Human Body. Saunders, Philadelphia, 1984.

[41] Guyton, A.C., Crowell, J.W., and Moore, J.W. Basic oscillating mechanism of Cheyne-Stokes breathing. Amer.J.Physiol., 187:395-398, 1956.

[42] Haddad, G.G. and Mellins, R.B. Hypoxia and respiratory control in early life. Ann. Rev. Physiol., 46:629-643, 1984.

[43] Haldane, J.S. and Priestley, J.G. The regulation of lung ventilation. J. Physiol. Lond., 32:225-266, 1905.

[44] Hathorn, M.K.S. The rate and depth of breathing in new-born infants in different sleep states. J. Physiol.London, 243(1):101-113, 1974.

[45] Hathorn, M.K.S. Analysis of periodic changes in ventilation in new-born infants. J. Physiol., 285:85-99, 1978.

[46] Henderson-Smart, D.J. Regulation of breathing in the fetus and newborn. In N.A. Saunders and C.E Sullivan, editors, Sleep and Breathing, pages 605-647. Marcel Dekker N.Y., 1994.

[47] Hlastala, M.P. and Berger, A.J. Physiology of Respiration. Oxford University Press, N.Y., 1996.

[48] Hoppenbrouwers, T. and Hodgman, J. Sleep respiratory behavior in normal term and preterm infants. IEEE Ninth Annual Conf. EMBS, 2:1106-1107, 1987.

[49] Hoppenbrouwers, T., Hodgman, J., and Cabal,L. Obstructive apnea,associated patterns of movement,heart rate and oxygenation in infants at low and increased risks for SIDS. Ped.Pulmon., 15(1):1-12, 1993.

[50] Hoppenbrouwers, T., Hodgman, J., Kazuka,A., Durand,M., and Cabal,L. Transcutaneous oxygen and carbon dioxide during the first half of life in premature and normal term infants. Ped.Res., 31(1):73-79, 1992.

[51] Horgan, J.D. and Lange, R.L. Digital computer simulation of the human respiratory system. IEEE International Conference Record, pages 149-157, 1963.

[52] Kahn, A., Groswasser, E., Rebuffat, E., and Sottiaux, M. et al. Sleep and cardiorespiratory characteristics of infant victims of sudden infant death:a prospective case-control study. Sleep, 15(4):287-292, 1992.

[53] Kappel, F. and Peer, R.O. A mathematical model for fundamental regulation processes in the cardiovascular system. J.Math. Biol., 31(6):611-631, 1993.

[54] Kelly, D.H. and Shannon, D.C. Periodic breathing in infants with near miss SIDS. Pediatrics, 63(3):355-360, 1979. 
[55] Khoo, M.C.K . A model for respiratory variability during non-REM sleep. In G.D. Swanson, F.S. Grodins, and R.L. Hughson, editors, Respiratory Control: modeling perspective, pages 327-336. Plenum Press. N.Y., 1990.

[56] Khoo, M.C.K. Modeling the effect of sleep state on respiratory stability. In M.C.K. Khoo, editor, Modeling and parameter estimation in respiratory control, pages 193-203. Plenum Press. N.Y., 1990.

[57] Khoo, M.C.K. Periodic breathing. In Grystal R. G. and West J.B. et al, editors, The Lung: scientific foundations, pages 1419-1431. Raven Press Ltd. New York, 1991.

[58] Khoo, M.C.K. Periodic breathing. In R.G. Crystal and J.B. et al West, editors, The Lung: Scientific Foundations, pages 1851-1863. Lippincott-Raven N.Y., 1997.

[59] Khoo, M.C.K., Gottschalk, A., and Pack, A.I. Sleep-induced periodic breathing and apnea: A theoretical study. J. Applied Physiol., 70(5):2014-2024, 1991.

[60] Khoo, M.C.K, Kronauer, R.E., Strohl, K.P., and Slutsky, A.S. Factors inducing periodic breathing in humans: a general model. J. Appl. Physiol., 53(3):644-659, 1982.

[61] Khoo, M.C.K. and Kronauer,R.E. Estimation of cardiopulmonary parameters for quasioptimal inputs. 1983 Proc. 2nd Am. Control Conf., pages 46-51, 1.

[62] Khoo, M.C.K. and Yamashiro, S.M. Models of Control of Breathing. In Chang, H.A. and Paiva, M., editors, Respiratory Physiology: an analytical approach, pages 799-829. Marcel Dekker, 1989.

[63] Koch,G. Alveolar ventilation, diffusing capacity and the A-a $\mathrm{PaO}_{2}$ difference in the newborn infant. Respir.Physiol., 4:168-192, 1968.

[64] Krous, H. F. The Pathology of Sudden Infant Death Syndrome: an overview. In J.L. Culbertson, H.F. Krous, and R.D. Bendell, editors, Sudden Infant Death Syndrome, Medical Aspects and Psychological Management, pages 18-47. John Hopkins Univ. Press. Baltimore, 1988.

[65] Lambertsen, C.J. Chemical control of respiration. In Mountcastle,V.B, editor, Medical Physiology, pages 1447-1487. C.V.Mosbey, 1980.

[66] Lamm, C. Sleep-disordered breathing in children. Mt. Sinai. J. Med., 61(2):131-138, 1994.

[67] Lloyd, B.B. and Cunningham, D.J.C. A quantitative approach to the regulation of human respiration. In Cunningham D.J.C and Lloyd B.B., editors, The Regulation of Human Respiration, pages 331-349. Blackwell Scientific Publications, Oxford, 1963.

[68] Lo,E.(lo@asuws1.dnet.nasa.gov) and Jackiewicz,Z.(jackiewi@zjsun.la.asu.edu). SNDELLM code, 1992.

[69] Longobardo, G.S. and Cherniack, N.S. Abnormalities in respiratory rhythm. In A.P. Fishman, editor, Handbook of Physiology: The Respiratory System, pages 729-749. American Physiology Society, 1986.

[70] Longobardo, G.S., Cherniack, N.S., and Gothe, B. Factors affecting respiratory system stability. Annal. Biomed. Eng, 17(4):377-396, 1989.

[71] Longobardo, G.S., Cherniak, N.S., and Fishman, A.P. Cheyne-Stokes breathing produced by a model of the human respiratory system. Journal of Applied Physiology, 21(6):1839-1846, 1966.

[72] Longobardo, G.S., Gothe, B., Goldman, M.D., and Cherniack, N.S. Sleep apnea considered as a control system instability. Resp. Physiol., 50:311-333, 1982.

[73] Longo,L.D. and Nystrom,G.A. Fetal and newborn respiratory gas exchange. In R.G. Crystal, J.B. West, P.J. Barnes, N.S. Cherniack, and E.R. Weibel, editors, The Lung: Scientific Foundations, pages 2141-2149. Lippincott-Raven N.Y., 1997.

[74] Martin,R.J., Okken,A.R., and Rubin,D. Arterial oxygen tension during active and quiet sleep in the normal neonate. J.Ped., 94(2):271-274, 1979.

[75] Mathew, R.J. Development of pulmonary circulation: Metabolic aspects. In R.A. Polin and W.W. Fox, editors, Fetal and Neonatal Physiology Volume 1, pages 678-682. W.B. Saunders, Philadelphia, 1992.

[76] McNamara, F. and Sullivan, C.E. Sleep disordered breathing and its effects on sleep in infants. Sleep, 19(1):4-12, 1996 .

[77] Milhorn, H.T. Jr., Benton, R, Ross, R., and Guyton, A.C. A mathematical model of the human respiratory control system. Biophys., 5:27-46, 1965.

[78] Miller, J.P., Cunningham,D .J., Lloyd, B.B., and Young, J.M. The transiient respiratory effects in man of sudden changes in alveolar $\mathrm{CO}_{2}$ in hypoxia and high $\mathrm{O}_{2}$. Respr. Physiol., $20(1): 17-31,1974$.

[79] Milner,A. Adaptation at birth. In A. Greenough, N.R. Roberton, and A. Milner, editors, Neonatal Respiratory Disorders, pages 48-56. Arnold, London, 1996.

[80] Mines, A.H. Respiratory Physiology. Raven Press, N.Y. N.Y., 1986.

[81] Mok,J.Y., McLaughlin,F.J., Pintar,M., Hak,H., Amarogalvez,R., and Levison,H. Transcuta- 
neous monitoring of oxygenation: What is normal? J.Pediatr., 108(3):365-371, 1986.

[82] Murray, J.F. ed. The Normal Lung. W.B. Saunders, N.Y. N.Y., 1986.

[83] Naughton, M., Benard, D., Tam,A., Rutherford,R., and Bradley,T.D. Role of hyperventilation in the pathogenesis of central sleep apneas in patients with congestive heart failure. AmRev-Respir-Dis., 148(2):330-338, 1993.

[84] Naughton, M.T., Benard, D.C., Rutherford,R., and Bradley,T.D. Effect of continuous positive airway pressure on central sleep apnea and nocturnal $P_{\mathrm{CO}_{2}}$ in heart failure. Am.J.Respir.Crit.Care Med., 150(6 pt.1):1598-1604, 1994.

[85] Nelson, N. Respiration and circulation after birth. In C.A. Smith and N.M. Nelson, editors, Physiology of the Newborn Infant, pages 200-250. Thomas,Springfield Ill., 1976.

[86] Nugent, S.T. and Finley, J.P. Spectral analysis for periodic and normal breathing in infants. IEEE Trans. Biomed. Eng., 30(1):672-675, 1983.

[87] Nugent, S.T., Tan,G.A., and Finley, J.P. A nonlinear model study of PB in infants. Proc. Ninth Annual Conf. IEEE EMBS, 2:1108-1110, 1987.

[88] Nunn, J.F. Applied Respiratory Physiology. Butterworths Press, Boston.Mass., 1987.

[89] Pack, A.I. General physiology of sleep. In R.G. Crystal, J.B. West, P.J. Barnes, N.S. Cherniack, and E.R. Weibel, editors, The Lung: Scientific Foundations, pages 2055-2061. Lippincott-Raven N.Y., 1997.

[90] Pallot, D. J. Control of Respiration. Oxford University Press, N.Y., 1983.

[91] Parisi, R.A., Neubauer, J.A., Frank,M.M., Edelman,N.H, and Santiago,T.V. Correlation between genioglossal and diaphragmatic responses to hypercapnia during sleep. Amer.Rev.Resp.Dis., 135:378-382, 1987.

[92] Parmalee, A.H., Stern, E, and Harris, M.A. Maturation of respiration in premature and young infants. Neuropadiatrie, 3(3):294-304, 1972

[93] Peterson, D.R. . Epidemiology of Sudden Infant Death Syndrome. In J.L. Culbertson, H.F. Krous, and R.D. Bendell, editors, Sudden Infant Death Syndrome, Medical Aspects and Psychological Management, pages 3-17. John Hopkins Univ. Press. Baltimore, 1988.

[94] Phillipson, E.A. Control of beathing during sleep. Am. Rev. Resp. Disease, 118(5):909-939, 1978.

[95] Polin,R.A. and Fox,W.W. Fetal and Neonatal Physiology Vols. 1 and 2. W.B. Saunders, Philadelphia, 1992.

[96] Pryor, W.W. Cheyne-Stokes breathing in patients with cardiac enlargment and prolonged circulation time. Circulation, 4:233-238, 1951.

[97] Read, D. and Henderson-Smart, D. Regulation of breathing in the newborn during different behavioral states. Ann. Rev. Physiol., 46:675-685, 1984.

[98] Rebuck, A.S., Slusky, A.S., and Mahutte, C.K. A mathematical expression to describe ventilatory response to hypoxia and hypercapnia. Res. Physiol., 31:107-116, 1977.

[99] Remmers, J.E. Effects of sleep on control of breathing. In Widdicombe J.G., editor, Respiratory Physiology III, vol 23, Int.Rev. of Physiol, pages 111-147. University Park Press Baltimore Md., 1981.

[100] Revow, M., England, S.J., O'Beirne, H., and Bryan, C. A model of the maturation of respiratory control in the newborn infant. IEEE. Trans. Biomed. Eng., 36(4):414-423, 1989.

[101] Richardson, D.W., Wasserman, A.J., and Patterson Jr., J.L. General and regional circulatory response to change in blood $\mathrm{pH}$ and $\mathrm{CO}_{2}$ tension. J. Clin. Invest., 40:31-43, 1961.

[102] Rigatto, H. Control of ventilation in the newborn. In Ann. Rev. of Physiol., vol. 46, pages 661-674. 1984.

[103] Rigatto, H. and Brady, J.P. PB and apnea in preterm infants-hypoxia as a primary event. Pediatrics, 50(2):219-227, 1972.

[104] Saunders, N.A. and Sullivan, C.E., eds. Sleep and Breathing. Marcel Dekker, N.Y. N.Y., 1994.

[105] Scarparelli, E. Pulmonary Physiology :Fetus, Newborn, Child,Adolescent 2nd Edition. Lee and Febiger, Philadelphia, 1975 and 1990.

[106] Schafer, T., Schafer, D., and Schlafke,M. Breathing, transcutaneous blood gases, and $\mathrm{CO}_{2}$ responses in SIDS siblings and control infants during sleep. J.A ppl.Physiol., 74(1):88-102, 1993.

[107] Schechtman, V.L., Harper, R.M., Wilson, A.J., and Southall, D.P. Sleep state organization in normal infants and victims of SIDS. Pediatrics, 89(5):865-870, 1992.

[108] Schluter B., Buschatz D., and Trowitzsch E. Apnea characteristics of children who later died: comparison of sudden infant death with other causes of death. Wien-Med-Wochenschr., 146(13-14):321-323, 1996.

[109] Shannon, D.C., Carley, D.W., and Kelly, D.H. Periodic breathing: quantitative analysis and clinical description. Pediat. Pulmon., 4:98-102, 1988.

[110] Siner,B. and Carlo, W.A. Appendix. In W.A. Carlo and R.L. Chatburn, editors, Neonatal 
Respiratory Care 2nd Edition. Year Book Medical Publishers, Chicago, 1988.

[111] Southall, D.P. Role of apnea in the sudden infant death syndrome. Pediatrics, 80(1):73-84, 1988.

[112] Swanson, G.D., Grodins, F.S., and Hughson, K.L., eds. Respiratory Control: Modeling perspective. Plenum Press, N.Y. N.Y., 1990.

[113] Tehrani, F.T. Mathematical analysis and computer simulation of the respiratory system in the new born. IEEE Transactions on Biomedical Engineering, 40(5):475-481, 1993.

[114] Thach, B.T. . The potential role of airway obstruction in SIDS. In J.L. Culbertson, H.F. Krous, and R.D. Bendell, editors, Sudden Infant Death Syndrome, Medical Aspects and Psychological Management, pages 62-93. John Hopkins Univ. Press. Baltimore, 1988.

[115] Tishler,P.V., Redline,S., Ferrette,V., Hans,M.G., and Altose,M.D. The association of SIDS with obstructive sleep apnea. Am.J.Respir.Crit.Care Med., 153:1857-1863, 1996.

[116] Vade, A., Dolenga, M., and Habisohn-Schuck,C. Chloral hydrate sedation of children undergoing ct and mr imaging: safety as judged by American Academy of Pediatrics guidelines. AJR-Am-J-Roentgenol., 165(4):905-909, 1995.

[117] van Lunteren, E. Upper airway effects on breathing. In R.G. Crystal, J.B. West, P.J. Barnes, N.S. Cherniack, and E.R. Weibel, editors, The Lung: Scientific Foundations, pages 2073-2084. Lippincott-Raven N.Y., 1997.

[118] Vielle, B. and Chauvet, G. Mathematical study of periodic breathing as an instability of the respiratory system. Math.Biosc., 114(2):149-172, 1993.

[119] Vulliamy,D.G. The Newborn Child Seventh Edition. Churchill Livingstone, N.Y. N.Y., 1994.

[120] Waggener, T.B., Frantz, I.D., Stark, A.R., and Kronauer, R.E. Oscillatory breathing patterns leading to apneic spells in infants. J. Appl. Physiol., 52(5):1288-1295, 1982.

[121] Waggener, T.B., Southall, D.P., and Scott,L.A. Analysis of breathing patterns in a prospective population of term infants does not predict susceptibility to SIDS. Ped.Res., 27(2):113$117,1990$.

[122] Waggener, T.B., Stark, A.R., Cohlan, B.A., and Frantz,I.D. Apnea duration is related to ventilatory oscillation characteristics in newborn infants. J. Appl. Physiol., 57(2):536544,1984

[123] Ward,S.L. and Marcus,C. Obstructive sleep apnea in infants and young children. J.Clin.Neurophysiol, 13(3):198-207, 1996.

[124] Warner,G., Skatrud, J., and Dempsey,J.A. Effect of hypoxia-induced PB on upper airway obstruction during sleep. J.Appl.Physiol., 62(6):2201-2211, 1987.

[125] Weiner, D., Mitra, J., Salamone, J., and Cherniack, N.S. Effect of chemical stimuli on nerves of upper airway muscles. J. Appl. Physiol., 52(3):530-536, 1982.

[126] West, J.B. Respiratory Physiology. Williams and Willaims Co., 1979. 